Check for updates

Cite this: Phys. Chem. Chem. Phys., 2021, 23, 11438

Received 9th March 2021, Accepted 30th April 2021

DOI: $10.1039 / d 1 c p 01052 b$

rsc.li/pccp

\section{High-temperature molecular screening of hybrid polyOAPS-imide networks based on octa(aminophenyl)silsesquioxane for increased thermomechanical resistance $\uparrow$}

\author{
Sylvie Neyertz, (D) *a Saman Salimi, (D) ${ }^{a}$ Farzaneh Radmanesh, ${ }^{b}$ Nieck E. Benes (D) ${ }^{b}$ \\ and David Brown (1D)
}

A new family of hybrid hyper-cross-linked thin films based on inorganic polyhedral oligomeric silsesquioxane (POSS) cages covalently bound with short organic imides has recently been developed using interfacial polycondensation followed by high-temperature imidization. These polyPOSS-imide networks were aimed at gas separations under harsh conditions, but the aliphatic arms of the initial POSS precursor, octa(aminopropyl)silsesquioxane, were found to be a weak link. This work investigates the replacement of the aliphatic arm by a phenyl derivative, octa(aminophenyl)silsesquioxane (OAPS). Although this new precursor is expected to be more thermoresistant, it introduces extra degrees of complexity since the functional $-\mathrm{NH}_{2}$ group on the phenyl ring can either be attached at a meta, a para or an ortho position. In order to avoid a costly programme of synthesis and testing, molecular dynamics (MD) simulations have been used to efficiently screen a large number of candidate structures based on mixtures of the three OAPS isomers, the initial POSS and three organic precursors, the PMDA, 6FDA and ODPA dianhydrides. Following cross-linking at room temperature, twenty-two model networks were further relaxed at the imidization temperature and directly tested under harsh conditions at $300{ }^{\circ} \mathrm{C}$. The screening stage included the characterization of their intercage single-links and double-links, which reinforce the structures, and intracage links, which have the opposite effect. Carrying out the cross-linking reactions to completion significantly improved the resistance to isotropic dilation. The initial POSS as well as the flexible 6FDA and ODPA linkers were found to be prone to large deformations, whereas the orthoOAPS, metaOAPS, paraOAPS and the PMDA linker prevented volume dilations. Upon uniaxial tension, the Young's moduli varied in the order paraOAPS $<$ POSS $\approx$ metaOAPS < orthoOAPS for the inorganic precursors and in the order 6FDA < ODPA < PMDA for the organic precursors. In all cases, the networks based on either orthoOAPS and/or PMDA displayed superior resistance. Nine polyOAPS-imides were further heated up to $400{ }^{\circ} \mathrm{C}$, i.e. closer to the expected degradation, and re-submitted to isotropic dilations and uniaxial tensions. They confirmed the trends found at $300{ }^{\circ} \mathrm{C}$ with no signs of structural collapse. Using OAPS as the inorganic precursor thus significantly reinforces the thermoresistance of these hybrid hyper-cross-linked networks. 
the cost-efficiency of the inorganic part. $^{8}$ Suitable inorganic candidates include the polyhedral oligomeric silsesquioxanes (POSS), ${ }^{9}$ with the basic formula $\left(\mathrm{RSiO}_{3 / 2}\right)_{n}$, which are siloxane cages functionalized with organic substituents $\mathrm{R}$ attached to the $\mathrm{Si}$ atoms. $n$ is commonly equal to $6,8,10$ or $12,,^{9,10}$ but the most extensively studied are the cubic $\mathrm{Si}_{8} \mathrm{O}_{12}$ cages functionalized with eight pendant organic arms. The POSS compounds can be fairly easily synthesized with good yields and functionalized with a wide variety of specific groups. ${ }^{9,11,12}$ Indeed, they have attracted a lot of interest in the field of nanomaterials as they can be blended, tethered or crosslinked to many polymers, ${ }^{13}$ amongst which the high-performance polyimides. ${ }^{14-17}$ Applications as separation membranes include gas separations, solvent separations, pressuredriven filtration, desalination and proton exchange membranes. ${ }^{18}$ However, they can show local phase separations. ${ }^{8,14,19,20}$

To overcome these processing difficulties, a new family of hyper-cross-linked thin films based on POSS covalently bound with very short organic imide moities has recently been developed using interfacial polycondensation. ${ }^{21-24}$ A primary amine-functionalized POSS in water is contacted with a dianhydride in toluene, which results in the formation of an homogeneous polyPOSS-(amic acid) thin film at the interface between the two immiscible solvents. The amic-acid groups are then converted to imides via thermal imidization, thus producing a polyPOSS-imide thin film. These facile synthesis conditions and the defect-free processability are well adapted to large-scale production. In addition, interfacial polycondensation can be directly carried out onto alumina hollow fibers, which efficiently support the thin films with high-surface-to-volume ratios. $^{25-27}$

The inorganic precursor used for the polycondensation of the first hyper-cross-linked polyPOSS-imides ${ }^{21-24}$ was an octa(aminopropyl)silsesquioxane functionalized with aliphatic $-\left(\mathrm{CH}_{2}\right)_{3}-\mathrm{NH}_{2}$ arms. Several organic precursors were considered, including the small and rigid pyromellitic dianhydride (PMDA), as well as the longer and more flexible $4,4^{\prime}$-(hexafluoroisopropylidene)diphthalic anhydride (6FDA) and 4,4'-oxidiphthalic anhydride (ODPA). Their chemical structures are provided in Fig. 1.

Upon contact at the interface, the dianhydride molecules react with the amine groups on the POSS to form the hypercross-linked networks. Since transport properties in polyimides are known to depend on the nature of the precursors, ${ }^{28}$ the intention was to fine-tune the networks towards specific gas separation applications. Although these new membranes were indeed able to perform under harsher conditions than conventional polymers, ${ }^{21,22}$ the $-\left(\mathrm{CH}_{2}\right)_{3}$ - links originating from the POSS precursor (Fig. 1) were found to be prone to thermal degradation above $\sim 300{ }^{\circ} \mathrm{C}$. Furthermore, molecular simulations ${ }^{29,30}$ showed that these aliphatic links deformed too easily and, consequently, that they could not impart any extra resistance to penetrant-induced dilation. This undermined the tuning of the gas separation properties under harsh conditions by using different imide linkers. ${ }^{31}$

This work investigates the replacement of the initial POSS precursor by a phenyl derivative ${ }^{11}$ in order to reinforce the thermomechanical resistance of the hybrid networks. OAPS, i.e. the octa(aminophenyl)silsesquioxane with the general formula $\mathrm{Si}_{8} \mathrm{O}_{12}-\left(\mathrm{C}_{6} \mathrm{H}_{4}-\mathrm{NH}_{2}\right)_{8}$ was selected as a potentially-interesting thermoresistant precursor. It has been shown to create H-bonds with surrounding polymer chains in blends. ${ }^{32}$ In addition, its $-\mathrm{NH}_{2}$ functionalization also allows for further reactions, including the polycondensation under study here, and indeed, OAPS was initially synthesized to provide a

(a) Initial inorganic precursor

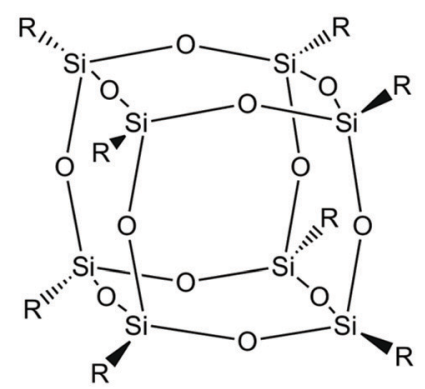

$$
\begin{gathered}
\text { POSS } \\
\mathrm{R}=-\left(\mathrm{CH}_{2}\right)_{3}-\mathrm{NH}_{2}
\end{gathered}
$$

(b) Organic precursors<smiles>O=c1oc(=O)c2cc3c(=O)oc(=O)c3cc12</smiles>

PMDA<smiles>O=C1OC(=O)c2cc(C(c3ccc4c(c3)C(=O)OC4=O)(C(F)(F)F)C(F)(F)F)ccc21</smiles>

6FDA<smiles>O=C1OC(=O)c2cc(Oc3ccc4c(c3)C(=O)OC4=O)ccc21</smiles>

ODPA

Fig. 1 Initial precursors for the hyper-cross-linked polyPOSS-imide thin films. ${ }^{21-24}$ The inorganic precursor (a) was a cubic octa(aminopropyl)silsesquioxane POSS cage with $-\left(\mathrm{CH}_{2}\right)_{3}-\mathrm{NH}_{2}$ arms and the organic precursors $(\mathrm{b})$ included the PMDA, 6FDA and ODPA dianhydrides. 


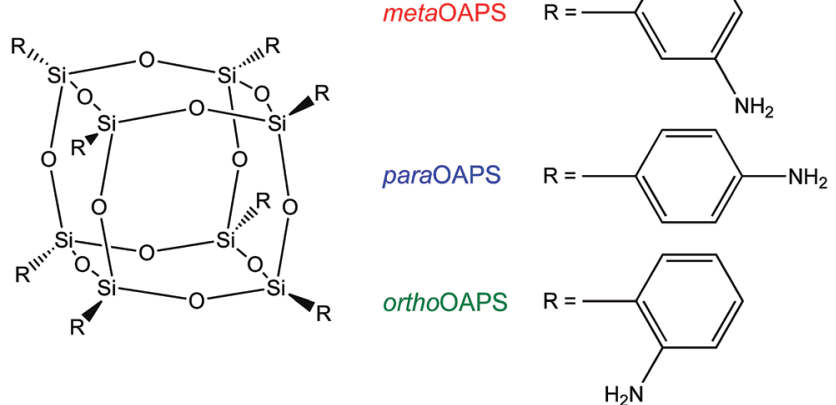

Fig. 2 The new octa(aminophenyl)silsesquioxane inorganic precursor (OAPS) and its three isomer forms for the aminophenyl arms.

nanoconstruction site for high-resistance hybrid materials. ${ }^{33}$ However, introducing monosubstituted phenyl rings means that the functional $-\mathrm{NH}_{2}$ group can either be attached at a meta, a para or an ortho position on the phenyl ring. There are thus three possible isomers for the aminophenyl arms of OAPS, which will be referred to as the metaOAPS, the paraOAPS and the orthoOAPS precursors (Fig. 2).

Molecular modelling techniques can be used to efficiently pre-screen a large number of candidate structures in order to avoid a costly programme of synthesis and testing. ${ }^{34}$ In particular, molecular dynamics (MD) simulations are able to provide information at the molecular level under a large variety of operating conditions, ${ }^{35}$ which is especially useful when harsh conditions have to be tested. Models of polyPOSS-PMDA and polyPOSS-6FDA based on the initial POSS precursor (Fig. 1) at one cross-link density have already been investigated. ${ }^{29,30,36}$ Here, a new set of molecular models are generated based on the three isomers of the OAPS precursor (Fig. 2) and the aforementioned PMDA, 6FDA and ODPA dianhydrides (Fig. 1) with several degrees of connectivity. The characteristics and thermomechanical resistance of the resulting polyOAPS-imide networks are compared to those of the corresponding polyPOSS-imides under harsh conditions, i.e. at $300{ }^{\circ} \mathrm{C}, 400{ }^{\circ} \mathrm{C}$ and under a large range of pressures.

Interestingly, it has been shown recently that OAPS crosslinked with long-chain polyimides can act as a plasticizer at very low contents, ${ }^{37}$ but that it significantly increases their glass transition temperature at higher contents. ${ }^{17,38}$ In addition, crosslinking with the shorter imides has also already attracted attention in an attempt to create microporous structures. ${ }^{11,39,40}$ The authors used a one-pot casting-curing process and reported processing difficulties associated with the gelation of the amic acid intermediates and the high viscosities for imidization. These first polyOAPS-imides were found to have a good thermostability, but they were not further investigated as no microporosity could be found. ${ }^{11,39,40}$ This lack of microporosity should definitely be an asset within the context of small gas separations. Furthermore, the interfacial polycondensation route is likely to improve their processability and lead to more-easily controlled microstructures.
As far as the isomers of the OAPS aminophenyl arms are concerned (Fig. 2), their relative proportions on the siloxane cages tend to vary according to the sources. The main synthesis route for OAPS is by nitration of octaphenylsilsequioxane (OPS) to first form octa(nitrophenyl)silsesquioxane (ONPS), followed by a reduction to transform the $-\mathrm{NO}_{2}$ into $-\mathrm{NH}_{2}$ groups. ${ }^{33,41,42}$ It was first reported that this synthesis led to a mixture of $50 \%$ of the meta isomer and $50 \%$ of the para isomer without any ortho substitution. ${ }^{33}$ This was later confirmed by several groups. ${ }^{43-45}$ However, a work based on the Si-C cleavage of ONPS reported that the nitro groups of ONPS (and hence the amino groups of OAPS) were attached at $70 \%$ in the meta position, at $25 \%$ in the ortho position and at $5 \%$ in the para position. ${ }^{41}$ It is unclear why the para isomer would be so prohibited. This question also arose in the one-potsynthesized polyOAPS-imides, where the significant ortho substitution should have hindered the completion of the imidization more than it did. ${ }^{39}$ Other reports quote the relative proportions of meta:ortho:para isomers as being either $60 \%: 30 \%: 10 \%{ }^{39,46}$ or $80 \%: 5 \%: 15 \% .^{47}$ Although there is a general consensus on the meta isomer accounting for at least for $50 \%$ of the arms, the proportions of the various isomers thus remain ill-defined.

An alternative route often used for other silsesquioxanes ${ }^{10}$ is the direct synthesis of OAPS from suitable functionalized silanes. Although it has been less explored up to now for their phenyl subclass, ${ }^{48}$ the use of aminophenyltrialkoxysilanes should allow for pure isomers of OAPS to be built by using the appropriate precursors only. This has indeed been attempted for the pure metaOAPS and paraOAPS structures, but the synthesis route led to mixtures of cage sizes ranging from 8 to 14 silicon units. ${ }^{48}$ This approach is thus able to better control the proportions of the isomers but its downside is that, up to now, the cage sizes seem to be less well controlled than in the nitration/reduction route from OPS to OAPS. ${ }^{33,41,42}$

In the present molecular screening work, the goal is to clearly assess the effects of the various isomers and their resistance under harsh conditions. As such, the metaOAPS, paraOAPS and orthoOAPS were all considered as separate inorganic precursors along with the PMDA, 6FDA and ODPA dianhydrides as organic precursors. Nine polyOAPS-imides were generated with two different cross-linking densities and compared to the two former polyPOSS-imides at $300{ }^{\circ} \mathrm{C}^{29,30}$ Following this first screening stage under harsh conditions on twenty-two models, nine polyOAPS-imides were further heated and investigated at $400{ }^{\circ} \mathrm{C}$, which is closer to the experimental degradation temperature for OAPS/polyimide nanocomposites. ${ }^{37,38}$ In addition, a large series of isotropic dilation and unaxial tension tests were carried out at both $300{ }^{\circ} \mathrm{C}$ and $400{ }^{\circ} \mathrm{C}$ for all systems under study, thus increasing the total number of simulations to 115.

The generation procedure for the model networks is detailed in Section 2. Section 3 presents the main screening stage for thermoresistance, which was carried out at $300{ }^{\circ} \mathrm{C}$. Section 4 reports the results obtained at $400{ }^{\circ} \mathrm{C}$ for the most thermoresistant networks. 


\section{Generation of the hyper-cross- linked networks}

The fully-atomistic polyOAPS-imide models were generated using a similar approach to cross-linked materials such as e.g. epoxies and other thermosets. ${ }^{49-60}$ The network connectivity is generated from an un-cross-linked monomer mixture using a heuristic distance criteria. ${ }^{58}$ New bonds are formed either instantaneously or progressively, and that inevitably introduces strain in the structure, which has then to be relaxed. The details of the procedure (e.g. the choice of the reactants, the cutoff for bond formation, the cross-linking density, the relaxation steps, etc.) are usually chosen to mimick the experimental approach. While they have already been reported for our polyPOSS-imide models, ${ }^{29,30}$ the adaptation to multi-structural screening required a few changes, which are described below. Furthermore, the initial polyPOSS-PMDA and polyPOSS-6FDA models were re-built exactly in the same way than the polyOAPS-imides in order to compare them for the same construction protocol.

\subsection{Model parameters}

All MD simulations were carried out with the $g m q$ parallel code, ${ }^{61}$ using a time step of $\Delta t=1 \mathrm{fs}$ in the integration algorithm. The total potential energy $U_{\text {pot }}$ was calculated from eqn (1), which describes the angle-bending, torsional, out-of-plane, van der Waals and electrostatic interactions in the molecules:

$$
\begin{aligned}
U_{\text {pot }}= & \sum_{\theta} U_{\text {bend }}(\theta)+\sum_{\tau} U_{\text {tors }}(\tau)+\sum_{i \text {-planar }} U_{\text {oop }}(i) \\
& +\sum_{(i, j) n b} U_{\mathrm{vdw}}(r)+\sum_{(i, j) n b} U_{\text {coul }}(r)
\end{aligned}
$$

The analytical forms of each term in eqn (1) are detailed in the ESI, $\uparrow$ along with the atom-types for OAPS-based molecules (Table S1, ESI $\dagger$ ). To ensure the equipartition of kinetic energy, high-frequency modes such as bond stretching or fast motions of the hydrogens in explicit $\mathrm{CH}, \mathrm{CH}_{2}$ and $\mathrm{NH}_{2}$ groups were removed using constraint algorithms. ${ }^{62,63}$ The force-field parameters were either calculated from Density Functional Theory (DFT) optimizations or adapted from the literature. ${ }^{64-66}$ This amounted to over 400 parameters for the present screening, most of them being partial charges. Indeed, these are known to be highly dependent on the environment (Fig. S1, ESI $\dagger$ ). All other OAPS-based parameters are provided in Tables S2 and S3 of the ESI $\uparrow$ along with the cutoffs for nonbonded interactions. The corresponding parameters for the aliphatic POSS-based networks have already been published. ${ }^{29,30}$

The temperature $T$, the isotropic pressure $p$ and the pressure tensor $P$ were maintained at the required values by loosecoupling $^{67,68}$ with relaxation times of $0.1 \mathrm{ps}$ for $T$ and $5 \mathrm{ps}$ for the pressures. The MD simulations were run under different conditions:

(1) constant-volume NVT conditions with a constant number of atoms $N$, a constant volume $V$ and a controlled temperature $T$ during the short initial relaxation steps (typically up to $10 \mathrm{ps}$ ).
(2) constant-isotropic-pressure $N p T$ conditions for the un-cross-linked mixtures (simulations times up to $5 \mathrm{~ns}$ per mixture), in which $p$ is controlled and the cubic box relaxes towards its equilibrium size.

(3) constant-pressure NPT conditions for the cross-linked networks (simulation times up to $20 \mathrm{~ns}$ per network), in which the box size and shape vary in response to the required pressure tensor $\boldsymbol{P}$, with its on-diagonal components being set to $1 \mathrm{bar}$ and its off-diagonal components being set to zero. NPT conditions are also used with a time-varying required pressure tensor when performing the isotropic dilation and uniaxial tension tests.

The cross-linking procedure was carried out at room temperature $\left(22^{\circ} \mathrm{C}\right)$ and the networks were then relaxed at $300{ }^{\circ} \mathrm{C}$ to mimick the experimental imidization stage. Since these molecules are aimed at being highly thermoresistant, the screening was directly carried out at $300{ }^{\circ} \mathrm{C}$. The best polyOAPSimides were further tested at $400{ }^{\circ} \mathrm{C}$. The resistances to mechanical stresses were obtained by modifying the ondiagonal components of the required pressure (dilation) or the $y y$ component of the pressure tensor (uniaxial tension) at a rate of -1 bar ps $^{-1}$ and recording the associated changes in volumes and extensions. All systems were visualized using the VMD software, ${ }^{69}$ the average thermodynamic data were stored every 1 ps and the configurations every 5 ps.

\subsection{The dianhydride:OAPS un-cross-linked mixtures}

For the experimental films based on the initial inorganic precursor, the average number of imide links per POSS was measured to be $\sim 4$ using X-ray photoelectron spectroscopy. ${ }^{23}$ This amounted roughly to a $2: 1$ dianhydride:POSS ratio. When attempting to model these structures, ${ }^{29,30}$ the number of POSS was set to 216 in order to have $\sim 30000-40000$ atoms in the networks, which is consistent with the largest epoxy models. ${ }^{5,56}$ As discussed before, ${ }^{29,30}$ the polycondensation reactions under study here have been shown to be governed by the high reactivity of both the amines on the inorganic precursors and the anhydrides on the organic precursors and to remain confined to the liquid-liquid interface. ${ }^{70}$ Consequently, the model reactants were created as bulks rather than as solutions, which would have increased tremendously the number of atoms at such high dilutions. The optimum dianhydride: POSS ratio for the starting mixtures was found to be $3: 1$ since a slight excess of dianhydride leads to more cross-linking possibilities and the unreacted dianhydrides can easily be removed from the final $2: 1$ networks. $^{29,30}$ Well-dispersed mixtures were obtaining by affinely scaling a 216-molecule POSS bulk and superimposing it with a large dense dianhydride box of side length $\sim 100-120 \AA$, which ensured that there were enough non-overlapping dianhydride molecules to select. The same optimised parameters were used in the present work, i.e. the OAPS bulks contained 216 molecules, the dianhydride bulks were large and the dianhydride: OAPS mixtures were prepared with a $3: 1$ stœechiometric ratio.

Before mixing both precursors, the models first have to be prepared in the pure phase. Three 216-molecule metaOAPS, paraOAPS and orthoOAPS and three larger $\sim 4000$-molecule 
Table 1 The OAPS and ODPA bulk monomer models at $22^{\circ} \mathrm{C}$. In this table and all following ones, the standard errors are the maximum ones obtained over a production run

\begin{tabular}{|c|c|c|c|c|}
\hline \multirow[b]{2}{*}{ No. of molecules } & \multicolumn{4}{|c|}{ metaOAPS paraOAPS orthoOAPS ODPA } \\
\hline & 216 & & & 4020 \\
\hline No. of atoms & 26784 & & & 116580 \\
\hline $\begin{array}{l}\text { Density } \rho_{\text {bulk }} \text { in } \mathrm{g} \mathrm{cm}^{-3} \\
( \pm 0.004)\end{array}$ & 1.322 & 1.316 & 1.321 & 1.552 \\
\hline Box length $L$ in $\AA( \pm 0.06)$ & 67.90 & 67.99 & 67.92 & 110.09 \\
\hline $\begin{array}{l}\text { Volume per molecule in } \AA^{3} \\
( \pm 4)\end{array}$ & 1449 & 1455 & 1451 & 332 \\
\hline $\begin{array}{l}\text { Length per molecule in } \AA \\
( \pm 0.01)\end{array}$ & 15.49 & 17.44 & 10.25 & 10.26 \\
\hline
\end{tabular}

PMDA, 6FDA and ODPA bulk boxes were prepared under $N p T$ conditions at $22{ }^{\circ} \mathrm{C}$ according to the procedure described previously. ${ }^{29,71}$ While the PMDA and 6FDA models have already been validated, ${ }^{29,30}$ this remained to be done for OAPS and ODPA. Table 1 displays their average equilibrium bulk densities $\rho_{\text {bulk, }}$, relaxed box lengths $L$ and molecular dimensions. For the OAPS isomers, the "length" is defined as twice the average distance between the centre of a siloxane cage and its eight primary amine N. For ODPA, it is the average distance between both anhydride $\mathrm{O}$.

To validate the model of OAPS, the actual chemical was purchased from Gelest Inc., which uses the nitration/reduction route (i.e. it contains mixtures of three isomers), and its density was measured using helium pycnometry. The experimental value for the powder was found to be $\sim 1.38-1.39 \mathrm{~g} \mathrm{~cm}^{-3}$ at $\sim 22{ }^{\circ} \mathrm{C}$, which is reasonably close to the model $\rho_{\text {bulk }}$ for all three OAPS isomers. For ODPA, $\rho_{\text {bulk }}$ is within less than $1 \%$ of its experimental value. ${ }^{72}$ As expected, the molecular dimensions of the isomers vary as orthoOAPS $<$ metaOAPS $<$ paraOAPS. For the dianhydrides, the ODPA is slightly longer in the pure state than 6FDA $(\sim 9.6 \AA)$, since the latter is more bent, ${ }^{29}$ whereas the shorter PMDA has a length of $\sim 6.7 \AA^{30}$

$3: 1$ mixtures were obtained by selecting the 648 dianhydrides that overlapped the least with the 216 OAPS and these were then heated up to $300{ }^{\circ} \mathrm{C}$ under $N p T$ conditions to relax the systems. Once their density had stabilized, they were cooled back to $22{ }^{\circ} \mathrm{C}$ at a rate of $-0.1{ }^{\circ} \mathrm{C} \mathrm{ps}^{-1}$ and relaxed for $5 \mathrm{~ns}$. Schematic representations of the final 3:1 PMDA:metaOAPS, 6FDA : metaOAPS and ODPA:metaOAPS systems are provided in Fig. 3. Both components (the OAPS in red and the dianhydrides in blue) are clearly well mixed. Table 2 reports the characteristics of the model mixtures.

With respect to the pure OAPS (Table 1), the mixture densities $\rho_{\text {mixture }}$ increase as the pure dianhydrides are denser. All three isomers seem to have approximately the same ability to pack. On the other hand, the effect of the dianhydride is more significant with ODPA $<$ PMDA $<6$ FDA, which can be related both to their densities in the pure phase $\mathrm{e}^{29,30}$ and their ability to pack efficiently. The mixture volumes $V_{\text {mixture }}$ are consistent with the ideal mixing volumes $V_{\text {ideal }}$ (as obtained from the volume per molecule for the pure OAPS and dianhydrides, see Table 1 and ref. 29 and 30), which confirms that all the mixtures are properly relaxed. All nine 3:1 dianhydride:OAPS mixtures were used as starting points for the crosslinking along with the 3:1 PMDA:POSS and 6FDA:POSS mixtures obtained earlier. ${ }^{29,30}$

\subsection{The cross-linking procedure}

The experimental procedure for generating hyper-cross-linked polyPOSS-imides networks is summarized in Fig. S2 (ESI $\dagger$ ) and involves three steps: ${ }^{21-24}$ (i) the preparation of two immiscible POSS and dianhydride solutions, which are then put in contact. (ii) the polycondensation at the interface which cross-links the

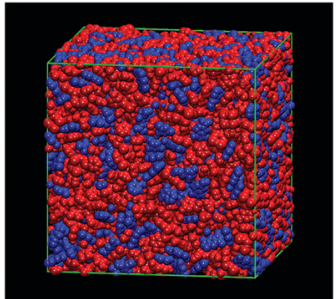

PMDA:metaOAPS

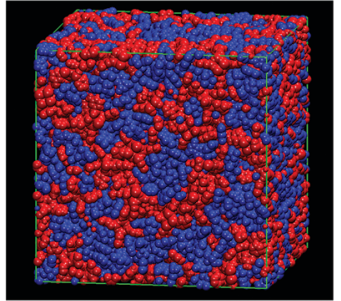

6FDA:metaOAPS

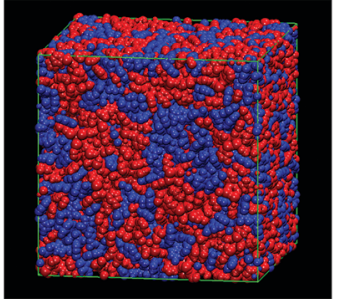

ODPA:metaOAPS

Fig. 3 The relaxed 3:1 dianhydride : metaOAPS mixtures. The OAPS and dianhydrides are shown as space-filling red and blue models, respectively. The lengths of the cubic boxes range from 76 to $84 \AA$.

Table 2 Characteristics of the un-cross-linked 3:1 dianhydride:OAPS mixtures at $22^{\circ} \mathrm{C}$

\begin{tabular}{|c|c|c|c|c|c|c|c|c|c|}
\hline & $\begin{array}{l}\text { metaOAPS } \\
+ \text { PMDA }\end{array}$ & $\begin{array}{l}\text { paraOAPS } \\
+ \text { PMDA }\end{array}$ & $\begin{array}{l}\text { orthoOAPS } \\
+ \text { PMDA }\end{array}$ & $\begin{array}{l}\text { metaOAPS } \\
+6 \mathrm{FDA}\end{array}$ & $\begin{array}{l}\text { paraOAPS } \\
+6 \mathrm{FDA}\end{array}$ & $\begin{array}{l}\text { orthoOAPS } \\
+6 \text { FDA }\end{array}$ & $\begin{array}{l}\text { metaOAPS } \\
+ \text { ODPA }\end{array}$ & $\begin{array}{l}\text { paraOAPS } \\
+ \text { ODPA }\end{array}$ & $\begin{array}{l}\text { orthoOAPS } \\
+ \text { ODPA }\end{array}$ \\
\hline No. of atoms & 38448 & & & 50760 & & & 45576 & & \\
\hline Density $\rho_{\text {mixture }}$ in $\mathrm{g} \mathrm{cm} \mathrm{cm}^{-3}( \pm 0.001)$ & 1.465 & 1.469 & 1.471 & 1.513 & 1.523 & 1.512 & 1.437 & 1.436 & 1.438 \\
\hline Box length $L$ in $\AA( \pm 0.1)$ & 76.2 & 76.1 & 76.1 & 83.8 & 83.7 & 83.9 & 80.4 & 80.4 & 80.4 \\
\hline Box volume $V_{\text {mixture }}$ in $\AA^{3}( \pm 60)$ & 442770 & 441520 & 440960 & 589480 & 585560 & 589930 & 520360 & 520440 & 519810 \\
\hline Ideal volume $V_{\text {ideal }}$ in $\AA^{3}$ & 449420 & 450570 & 448610 & 593440 & 594150 & 594840 & 527890 & 529850 & 528170 \\
\hline$V_{\text {mixture }} / V_{\text {ideal }}$ & 0.99 & 0.98 & 0.98 & 0.99 & 0.99 & 0.99 & 0.99 & 0.98 & 0.98 \\
\hline
\end{tabular}


precursors and generates the polyPOSS-(amic acid) networks and (iii) the thermal imidization at high temperatures up to $300{ }^{\circ} \mathrm{C}$, which transforms the amic acid groups into imides, thus leading to the final polyPOSS-imides. Here, the first step is mimicked by building the un-cross-linked mixtures (Section 2.2). In our previous work, ${ }^{29,30}$ the intermediate

(a) polymetaOAPS-6FDA

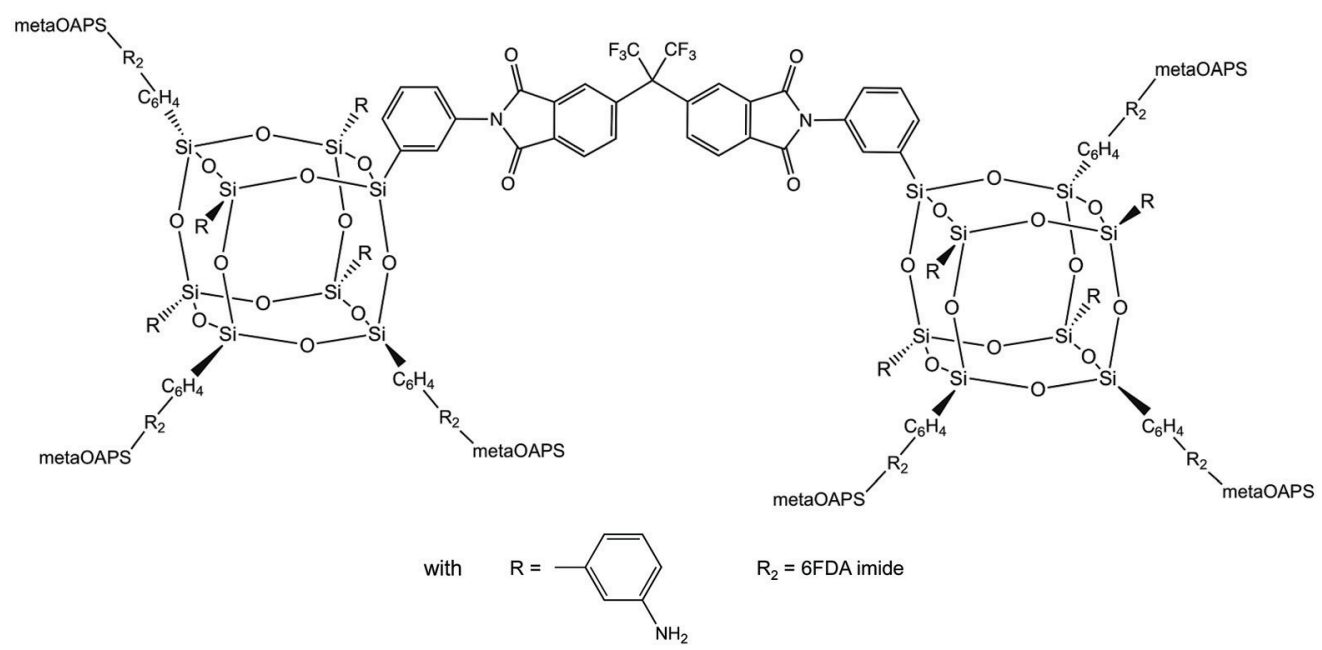

(b) polyparaOAPS-PMDA

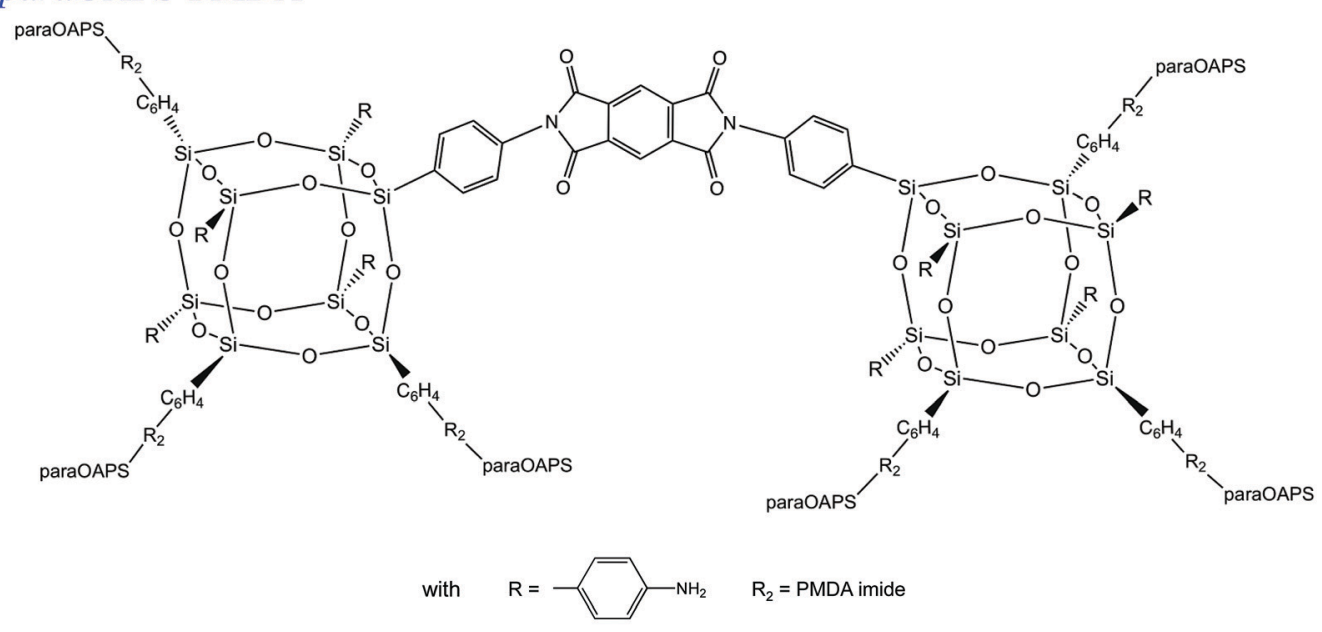

(c) polyorthoOAPS-ODPA

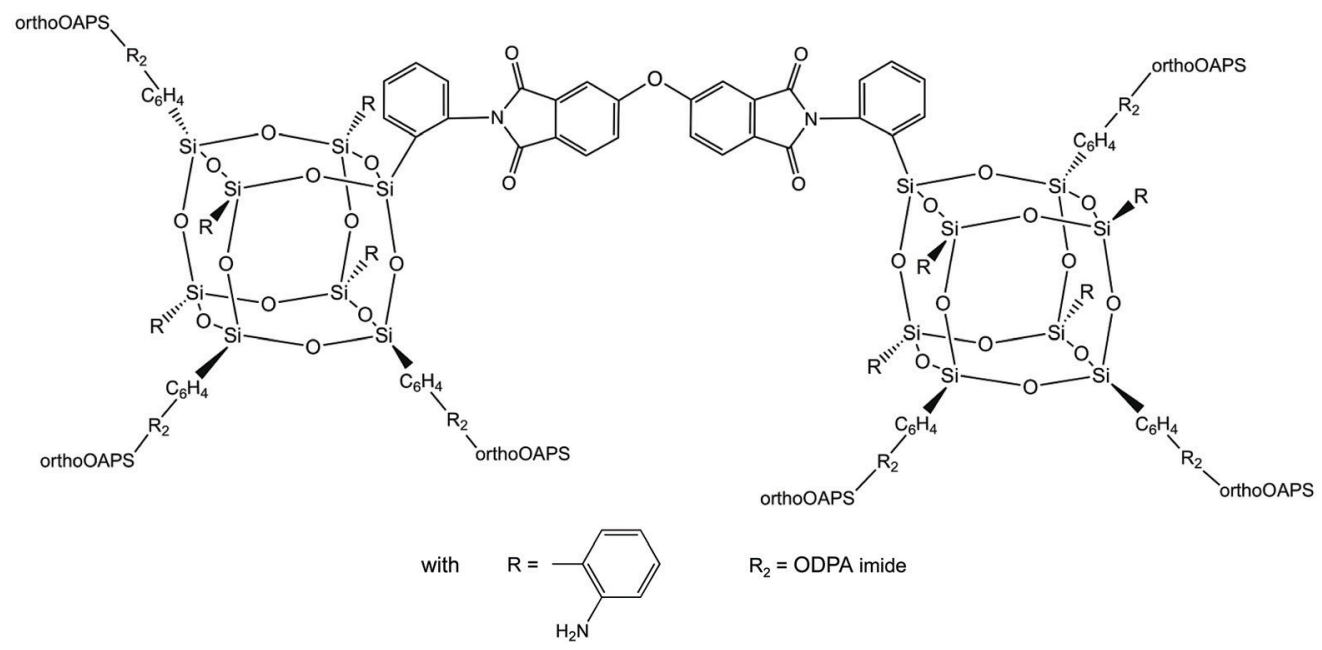

Fig. 4 Chemical structures of several polyOAPS-imides with an average connectivity of four links per OAPS cage. 
polyPOSS-(amic acid) step was explicitly modelled. Although this allowed us to assess the effects of thermal imidization, ${ }^{24}$ it introduced significant extra-complexity even though the connectivity of the final network is defined once the initial transformation to the polyPOSS-(amic acid) is made. We subsequently performed direct transformations of the mixtures into the final imide forms with the concomitant elimination of one $\mathrm{H}_{2} \mathrm{O}$ molecule per imidization. The resulting networks show very similar characteristics to those obtained using the "two-stage" amic acid/imidization transformation initially used for the polyPOSS-imide models ${ }^{29,30}$ (see Fig. S3 and Table S4 in the ESI $\dagger$ ). It is also much faster in terms of reaction times, and, as such, it was adopted for multi-screening purposes. The chemical structures of several cross-linked polyOAPS-imides are displayed in Fig. 4.

To model the transformation from the precursors to the polyOAPS-imides (Fig. 4), covalent bonds must be formed between the aminophenyl nitrogens $\mathrm{N}$ on the OAPS and each of the two ketone carbons $\mathrm{C}_{\mathrm{ket}}$ on the dianhydride. This occurs by breaking the bonds between the $\mathrm{C}_{\mathrm{ket}}$ and the anhydride oxygen $\mathrm{O}_{\text {anhy }}$. The $\mathrm{O}_{\text {anhy }}$ and the amine hydrogens are eliminated, which is tantamount to removing one water molecule per imidization reaction. ${ }^{21-24}$ Two new $\mathrm{C}_{\text {ket }}-\mathrm{N}$ bonds are then formed in place of the initial $\mathrm{C}_{\mathrm{ket}}-\mathrm{O}_{\text {anhy }}$ bonds and the structures are relaxed. Since experimental evidence on the polyPOSS-imides shows that none of the anhydride groups remain unreacted, ${ }^{21,22}$ it is assumed that both ends of a model dianhydride react at the same time to an amine $\mathrm{N}$ on different OAPS arms. The formation of the network is deemed to be complete when the required number of dianhydrides are connected to the inorganic precursors at both ends.

In practice, all distances between the dianhydrides $\mathrm{C}_{\mathrm{ket}}$ and the OAPS amine $\mathrm{N}$ were recorded, and only those dianhydrides having the sum, $R_{\min }$, of their shortest $\mathrm{C}_{\mathrm{ket}} \cdots \mathrm{N}$ distances at either end being less than a set limit criterion were selected. Based on $\mathrm{C}_{\mathrm{ket}} \cdots \mathrm{N}$ radial distribution functions in the mixtures, the limit was initially set to $R_{\min } \leq 6 \AA$ for polyPOSS-PMDA. ${ }^{29}$ It was later shown for polyPOSS-6FDA ${ }^{30}$ that using $R_{\min } \leq 7 \AA$ did not change the characteristics of the networks, but significantly reduced the time required to complete all reactions. As shown by Fig. S4 (ESI $\dagger)$, the $\mathrm{C}_{\text {ket }} \cdots \mathrm{N}$ distances are over $3 \AA$ in the dianhydride:orthoOAPS mixtures and the criterion for reactions was set to $R_{\min } \leq 7 \AA$ so as to allow imide bridges to be formed with all three OAPS isomers.

The cross-linking procedure ${ }^{29,30}$ was carried out progressively at $22{ }^{\circ} \mathrm{C}$, i.e. the dianhydrides with $R_{\min } \leq 7 \AA$ A were first selected to form OAPS-diimide links. To relax the introduced strains, the newly created $\mathrm{C}_{\mathrm{ket}}-\mathrm{N}$ bonds were relaxed back to their equilibrium bond length by a 1 ps-energy minimization using a harmonic flexible bond potential with a force constant of $100 \mathrm{~kg} \mathrm{~s}{ }^{-2}$. This was followed by a $1 \mathrm{ps} \mathrm{MD}$ run under constant-energy conditions to ensure that no stretched bonds nor any other high-energy interactions remained in the system. The network under construction was then gradually rethermalized with MD for 8 ps under NVT conditions. Following that phase, $R_{\min }$ was re-calculated for all remaining unreacted dianhydrides, and those being under $7 \AA$ were selected to form more bonds. The process continued until the network was complete and the excess unreacted dianhydrides were subsequently removed from the system.

Initially, the number of reactions were limited to 432 , i.e. a $2: 1$ dianhydride:POSS ratio in agreement with the average value of 4 links per POSS cage found experimentally. ${ }^{22}$ In the present case, the mixtures were also first cross-linked up to the same average connectivity of four links per OAPS. However, in reality, there is no reason for the reactions not being allowed to continue until completion and as such, a second set of samples was obtained by allowing cross-linking until there were either no more possible reactions or when further reactions led to steric hindrances that could not be relaxed out sufficiently to allow the MD to restart. This gave us two separate sets of polyOAPS-imide networks with different degrees of connectivity:

- 9 systems with an average connectivity of 4 links per OAPS.

- 9 systems with the reactions carried out to completion.

In addition, the polyPOSS-PMDA and polyPOSS-6FDA based on the aliphatic POSS precursor ${ }^{29,30}$ (Fig. 1) were regenerated under exactly the same conditions than the polyOAPS-imides, i.e. one system each with an average connectivity of 4 links per POSS and another one with the reactions carried out to completion.

For the systems with an average of 4 links per cage, the number of atoms forming a continuous network was typically found to be $>96 \%$. This increased to $>99 \%$ when the crosslinking reactions were carried out to completion. The few remaining atoms belonged either to unreacted cages or to small cage-dianhydride-cage blocks, which are likely to exist in the real systems as well. However, in spite of reaching a continuous network for both approaches, there is quite a large difference in terms of simulation time. The completion is significantly more expensive as it gets increasingly difficult to find unreacted dianhydrides within the $R_{\min }$ criterion. This is illustrated by Fig. 5 for the systems linked with the 6FDA dianhydride and in Fig. S5 (ESI $\dagger$ ) for those linked with PMDA and ODPA.

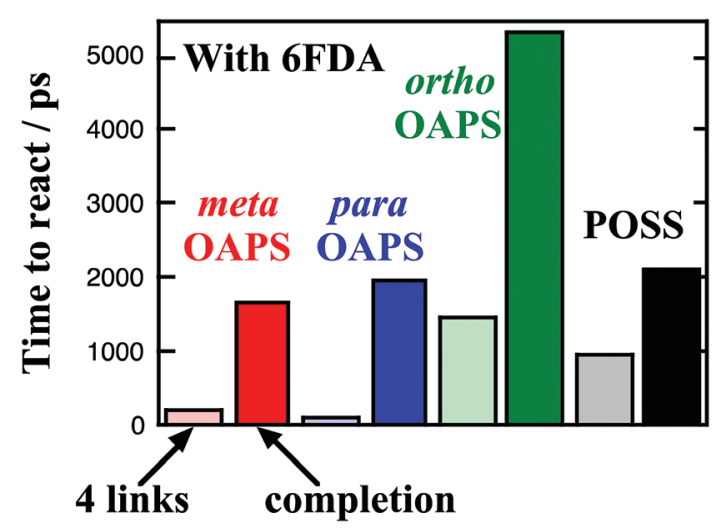

Fig. 5 Simulation times needed to reach an average connectivity of 4 links per cage (left bars) compared to those needed to go to completion (right bars) for the cross-linking procedure of the polyOAPS-6FDA and polyPOSS-6FDA systems. 
Table 3 Average model densities at $300{ }^{\circ} \mathrm{C}$ for the 22 networks under study

\begin{tabular}{|c|c|c|c|c|c|c|c|c|c|c|c|}
\hline Density at $300{ }^{\circ} \mathrm{C}$ & $\begin{array}{l}\text { metaOAPS } \\
+ \text { PMDA }\end{array}$ & $\begin{array}{l}\text { paraOAPS } \\
+ \text { PMDA }\end{array}$ & $\begin{array}{l}\text { orthoOAPS } \\
+ \text { PMDA }\end{array}$ & $\begin{array}{l}\text { POSS } \\
+ \text { PMDA }\end{array}$ & $\begin{array}{l}\text { metaOAPS } \\
+6 \mathrm{FDA}\end{array}$ & $\begin{array}{l}\text { paraOAPS } \\
+6 \mathrm{FDA}\end{array}$ & $\begin{array}{l}\text { orthoOAPS } \\
+6 \text { FDA }\end{array}$ & $\begin{array}{l}\text { POSS } \\
+6 \text { FDA }\end{array}$ & $\begin{array}{l}\text { metaOAPS } \\
+ \text { ODPA }\end{array}$ & $\begin{array}{l}\text { paraOAPS } \\
+ \text { ODPA }\end{array}$ & $\begin{array}{l}\text { orthoOAPS } \\
+ \text { ODPA }\end{array}$ \\
\hline $\begin{array}{l}\text { Average connectivity of } 4 \text { linl } \\
\left\langle\rho_{\text {network }}\right\rangle \text { in } \mathrm{g} \mathrm{cm}^{-3}( \pm 0.002)\end{array}$ & $\begin{array}{l}\text { ks per cage } \\
1.068\end{array}$ & 0.900 & 1.232 & 1.167 & 1.211 & 1.145 & 1.203 & 1.232 & 1.175 & 1.093 & 1.179 \\
\hline $\begin{array}{l}\text { Reactions carried out to com } \\
\left\langle\rho_{\text {network }}\right\rangle \text { in } \mathrm{g} \mathrm{cm}^{-3}( \pm 0.001)\end{array}$ & $\begin{array}{l}\text { pletion } \\
1.066\end{array}$ & 0.915 & 1.274 & 1.176 & 1.211 & 1.156 & 1.219 & 1.253 & 1.177 & 1.116 & 1.205 \\
\hline
\end{tabular}

Following their construction, the networks were run under $N P T$ conditions at $300{ }^{\circ} \mathrm{C}$ to mimick the conditions of the experimental imidization. The simulations were carried out for $20 \mathrm{~ns}$ in order to stabilize their densities and energies and store enough equilibrium data (Fig. S6 in ESI $\dagger$ ). Since these systems are aimed at being thermomechanically resistant, the main screening stage was directly carried out at $300{ }^{\circ} \mathrm{C}$, and the properties were averaged over the last $5 \mathrm{~ns}$ of the simulations.

\section{Screening of the polyOAPS-imides and the polyPOSS-imides at $300^{\circ} \mathrm{C}$}

\subsection{Densities and energies}

The relaxed densities at $300{ }^{\circ} \mathrm{C}, \rho_{\text {network }}$, are reported in Table 3 . All systems remained basically cubic.
The $\rho_{\text {networks }}$ decrease with respect to the $\rho_{\text {mixtures }}$ (Table 2), as the cross-links introduce steric hindrance, the unreacted dianhydrides are removed and the temperature is higher. Experimentally, the refractive indices of polyPOSS-imide films with either 6FDA or ODPA were found to be close to each other, and higher than those with PMDA. ${ }^{24}$ This is related to the flexible precursors being able to pack more efficiently than the small rigid PMDA. Furthermore, imidization results in the creation of an additional unrelaxed free volume in polyPOSSPMDA, ${ }^{24,29,30}$ hence its significantly lower density at similar degrees of connectivity. In the model polyOAPS-imides, there is a similar trend with respect to the organic linkers but the inorganic isomer has also an effect. It is not surprising that the ortho-isomers, that keep the linkages close to the cages lead to denser networks. On the other hand, the para-isomers allow for the cages being further away and, as such, the density

(a)
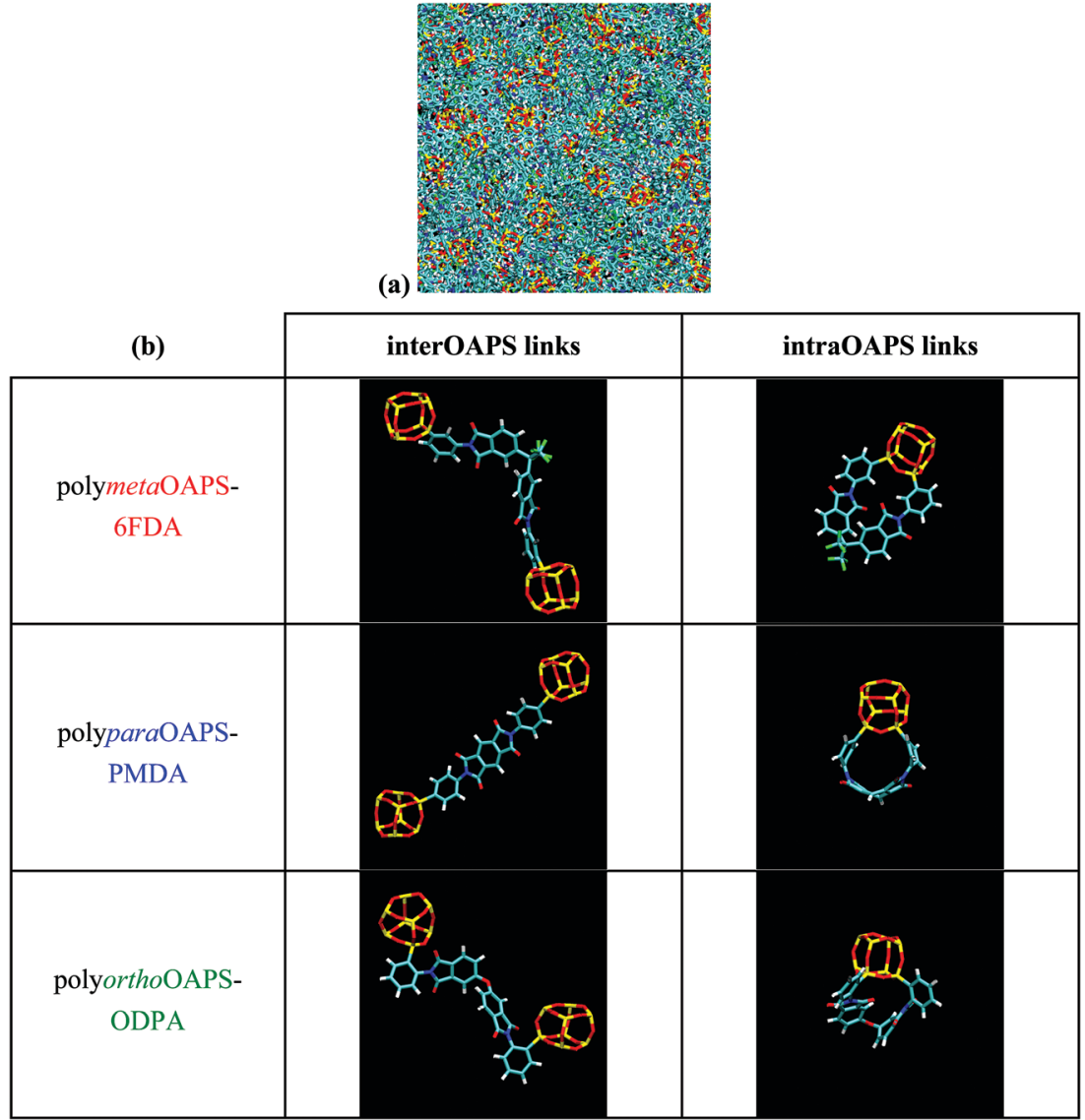

Fig. 6 Schematic representations of (a) a $(60 \AA)^{2}$ subset of the polymetaOAPS-6FDA network at $300{ }^{\circ} \mathrm{C}$ and (b) close-ups of typical interOAPS and intraOAPS links found in various networks. Colour code: yellow $=\mathrm{Si}$, red $=\mathrm{O}$, cyan $=\mathrm{C}$, blue $=\mathrm{N}$, green $=\mathrm{F}$, white $=\mathrm{H}$. 
decreases. The behaviour of the meta-isomers is intermediate. The corresponding energies, which are reported in Table S5 of the ESI, $\dagger$ show no signs of residual bending or torsional strains in the relaxed systems.

\subsection{Connectivities}

Hyper-cross-linked networks have a very high level of molecular complexity (Fig. 6a). As expected, their organic-inorganic links include dianhydrides being linked to two different cages, which are referred to as "interOAPS" (or “interPOSS") links. However, due to the geometry of polysilsesquioxanes, there are also dianhydrides attached to two arms of the same cage, which are referred to as "intraOAPS" (or "intraPOSS") links. Fig. 6b displays a representative subset of interOAPS and intraOAPS links.

The average number of intercage and intracage links are compared in Fig. 7 for all 22 structures using stack colums in order to show the total connectivities as well. An additional Figure showing separately the average numbers of intercage and intracage links is provided in Fig. S7 (ESI $\dagger$ ).

It is clear from Fig. 7 that both the nature of the cage and the dianhydrides affect the connectivity of the resulting networks.
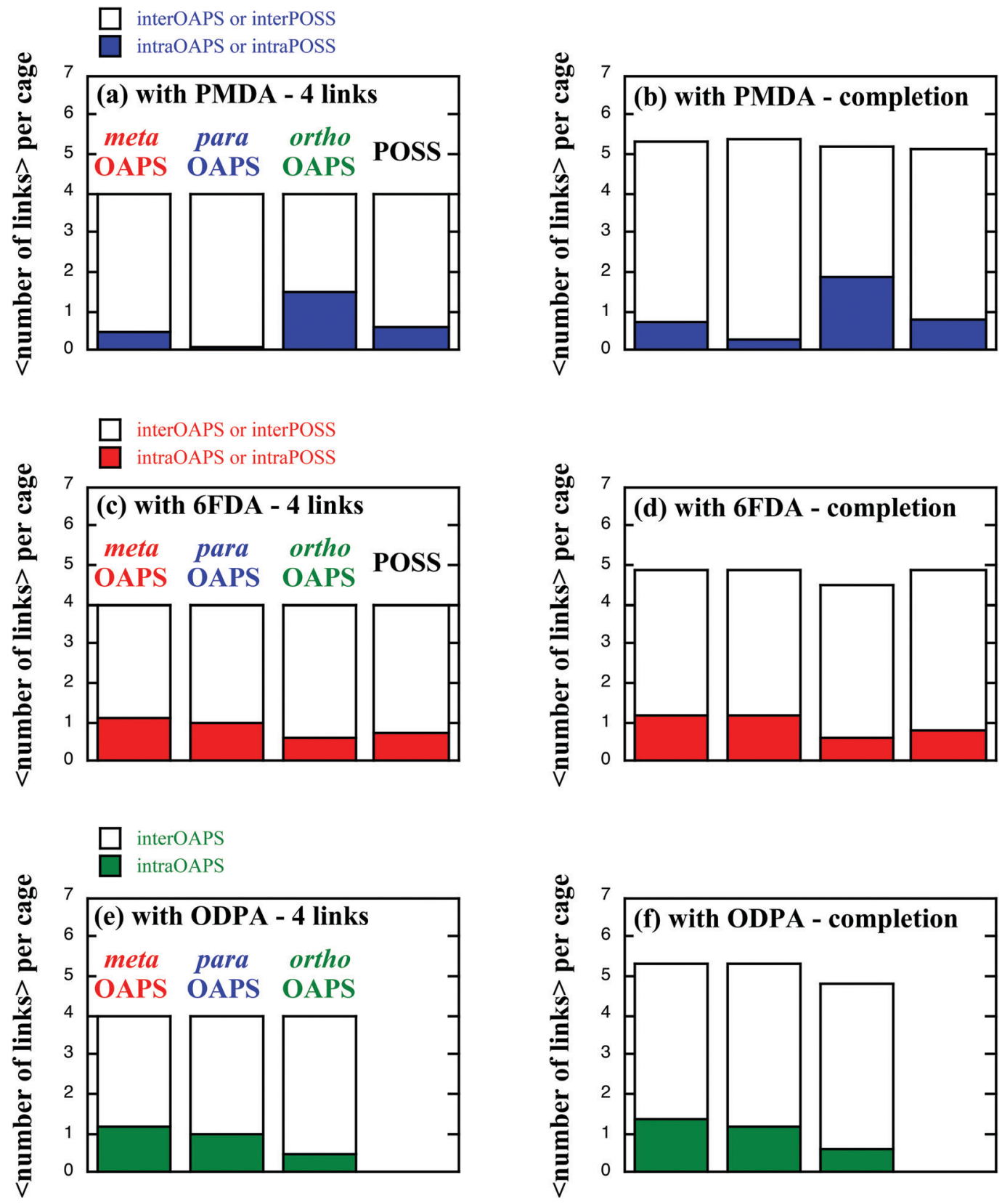

Fig. 7 Average number of intracage links (coloured bars) and intercage links (white bars) per cage in the 22 systems generated. The networks with an average connectivity of 4 links per cage (left figures) are compared to those with reactions carried out to completion (right figures). 
The trends are the same when the average connectivity per cage is four or when the reactions are carried out to completion, except that there are more links in the latter. Interestingly, there is no significant tendency for the increased number of reactions to favour intercage rather than intracage links: both increase and their relative proportions remain approximately the same. The possibility to obtain experimentally higher connectivities than the initially-determined ${ }^{22}$ average value of 4 was actually later confirmed for polyPOSS-6FDA, where increasing concentrations of the POSS precursor led to connectivities of up to 4.9 links per POSS. ${ }^{23}$ This is very close to the average connectivity found for the model polyPOSS-6FDA when carrying out the cross-linking reactions to completion (Fig. 7d). While there are no available experimental data for the other dianhydrides, the models suggest that both of them are able to achieve higher connectivities than 6FDA. Indeed, their molecular volumes vary in the order $\sim 215 \AA^{3}$ for PMDA $^{29}<$ $\sim 330 \AA^{3}$ for ODPA (Table 1) $<\sim 435 \AA^{3}$ for $6 \mathrm{FDA},{ }^{30}$ which enhances their cross-linking possibilities.

It might be expected that structures with a large number of intracage links will be less resistant to mechanical deformation than those where intercage links are more numerous. Within this context, there are two different trends for the polyOAPSimides depending on the inorganic isomer and the flexibility of the organic dianhydride. For the short rigid PMDA (Fig. 7a and b), the meta and para isomers create more intercage links than the aliphatic polyPOSS-PMDA, while the ortho isomer has a very large number of intracage links. For the more flexible 6FDA (Fig. 7c and d), the trend is reversed with the ortho isomer leading to a more favourable structure than the aliphatic polyPOSS-6FDA, while the para and meta isomers have a larger number of intraOAPS links. ODPA (Fig. 7e and f), which is flexible around its ether bridge, shows the same behaviour than 6FDA.

The differences between the isomers for the flexible organic linkers are reflected in the average intercage $\mathrm{N} \cdots$ centre $\cdots \mathrm{N}$ angles for the imides (with the imide centres being defined as the two middle aromatic carbons for PMDA, the $\left(\mathrm{CF}_{3}\right)_{2}$-carrying carbon for 6FDA and the ether oxygen for ODPA, see Fig. 1), which are reported in Table 4 . The average intercage Si $\cdots \mathrm{Si}$ distances, which are representative of the total length of the linkers (incorporating both the inorganic and organic parts) are also provided. Unlike PMDA, the 6FDA and ODPA $\mathrm{N} \cdots$ centre $\cdots \mathrm{N}$ angles are significantly more open in the ortho-based networks with respect to the corresponding para and meta isomers, thus reflecting the tendency to form more interOAPS links in the former. On the other hand, the shorter and rigid PMDA linker strongly reduces the average $\mathrm{Si} \cdot \mathrm{Si}$ distances in the ortho isomer and increases the steric constraints, thus favouring intraOAPS links in this case.

As reported previously for polyPOSS-imides, ${ }^{30,71}$ some intercage links can either be single, i.e. one link between two cages or double-links, i.e. two links between the same two cages, because of the multi-arm nature of the inorganic precursor. The latter case concerns $\sim 10-20 \%$ of the cages with only intercage links (Fig. S8, ESI $\dagger$ ) and seems to be slightly favoured in the systems where there are less intracage links. There is no significant dependence on whether the cage is an OAPS isomer or a POSS. Such double-links should re-inforce the resistance of the networks, but they also mean that the actual cross-linking density is less than the average number of intercage links per cage. Indeed, the numbers of different cages linked to a

Table 4 The interOAPS (or interPOSS) Si $\cdots$ Si distances and imide $\mathrm{N} \cdots$ centre $\cdots \mathrm{N}$ angles averaged at $300{ }^{\circ} \mathrm{C}$ for the 22 networks

\begin{tabular}{|c|c|c|c|c|c|c|c|c|c|c|c|}
\hline Intercage links & $\begin{array}{l}\text { metaOAPS } \\
+ \text { PMDA }\end{array}$ & $\begin{array}{l}\text { paraOAPS } \\
+ \text { PMDA }\end{array}$ & $\begin{array}{l}\text { orthoOAPS } \\
+ \text { PMDA }\end{array}$ & $\begin{array}{l}\text { POSS } \\
+ \text { PMDA }\end{array}$ & $\begin{array}{l}\text { metaOAPS } \\
+6 \mathrm{FDA}\end{array}$ & $\begin{array}{l}\text { paraOAPS } \\
+6 \mathrm{FDA}\end{array}$ & $\begin{array}{l}\text { orthoOAPS } \\
+6 \text { FDA }\end{array}$ & $\begin{array}{l}\text { POSS } \\
+6 \text { FDA }\end{array}$ & $\begin{array}{l}\text { metaOAPS } \\
+ \text { ODPA }\end{array}$ & $\begin{array}{l}\text { paraOAPS } \\
+ \text { ODPA }\end{array}$ & $\begin{array}{l}\text { orthoOAPS } \\
+ \text { ODPA }\end{array}$ \\
\hline \multicolumn{12}{|c|}{ Average connectivity of 4 links per cage } \\
\hline $\begin{array}{l}\langle\mathrm{Si} \cdots \mathrm{Si} \text { distances }\rangle \text { in } \AA \\
( \pm 0.02)\end{array}$ & 15.52 & 17.15 & 11.01 & 13.27 & 15.16 & 16.05 & 13.67 & 14.16 & 15.46 & 16.31 & 14.08 \\
\hline $\begin{array}{l}\langle\mathrm{N} \cdots \text { centre } \cdots \mathrm{N} \text { angles }\rangle \text { in } \\
\operatorname{deg}( \pm 0.1)\end{array}$ & 133.0 & 132.6 & 133.2 & 133.3 & 98.8 & 95.7 & 106.5 & 103.2 & 109.3 & 103.1 & 121.9 \\
\hline \multicolumn{12}{|c|}{ Reactions carried out to completion } \\
\hline $\begin{array}{l}\langle\mathrm{Si} \cdots \mathrm{Si} \text { distances }\rangle \text { in } \AA \\
( \pm 0.02)\end{array}$ & 15.45 & 16.81 & 11.17 & 13.35 & 15.26 & 15.89 & 13.78 & 14.53 & 15.56 & 16.59 & 14.21 \\
\hline $\begin{array}{l}\langle\mathrm{N} \cdots \text { Centre } \cdots \mathrm{N} \text { angles }\rangle \text { in } \\
\operatorname{deg}( \pm 0.1)\end{array}$ & 132.8 & 132.2 & 133.1 & 133.3 & 99.0 & 95.1 & 107.4 & 102.9 & 109.8 & 105.4 & 122.2 \\
\hline
\end{tabular}

Table 5 Average cross-linking densities for the 22 networks under study

\begin{tabular}{|c|c|c|c|c|c|c|c|c|c|c|c|}
\hline Cross-linking density & $\begin{array}{l}\text { metaOAPS } \\
+ \text { PMDA }\end{array}$ & $\begin{array}{l}\text { paraOAPS } \\
+ \text { PMDA }\end{array}$ & $\begin{array}{l}\text { orthoOAPS } \\
+ \text { PMDA }\end{array}$ & $\begin{array}{l}\text { POSS } \\
+ \text { PMDA }\end{array}$ & $\begin{array}{l}\text { metaOAPS } \\
+6 \text { FDA }\end{array}$ & $\begin{array}{l}\text { paraOAPS } \\
+6 \mathrm{FDA}\end{array}$ & $\begin{array}{l}\text { orthoOAPS } \\
+6 \text { FDA }\end{array}$ & $\begin{array}{l}\text { POSS } \\
+6 \text { FDA }\end{array}$ & $\begin{array}{l}\text { metaOAPS } \\
+ \text { ODPA }\end{array}$ & $\begin{array}{l}\text { paraOAPS } \\
+ \text { ODPA }\end{array}$ & $\begin{array}{l}\text { orthoOAPS } \\
\text { + ODPA }\end{array}$ \\
\hline $\begin{array}{l}\text { Average connectivity of } 4 \text { link } \\
\langle\text { No. of different cages linked } \\
\text { to a cage }\rangle\end{array}$ & $\begin{array}{l}3.3 \\
3.3 e r \text { cage }\end{array}$ & 3.6 & 2.3 & 3.2 & 2.8 & 2.8 & 3.2 & 3.1 & 2.7 & 2.8 & 3.2 \\
\hline $\begin{array}{l}\text { Reactions carried out to com } \\
\langle\text { No. of different cages linked } \\
\text { to a cage }\rangle\end{array}$ & $\begin{array}{l}\text { pletion } \\
4.2\end{array}$ & 4.7 & 3.0 & 4.0 & 3.4 & 3.5 & 3.6 & 3.7 & 3.6 & 3.8 & 3.8 \\
\hline
\end{tabular}



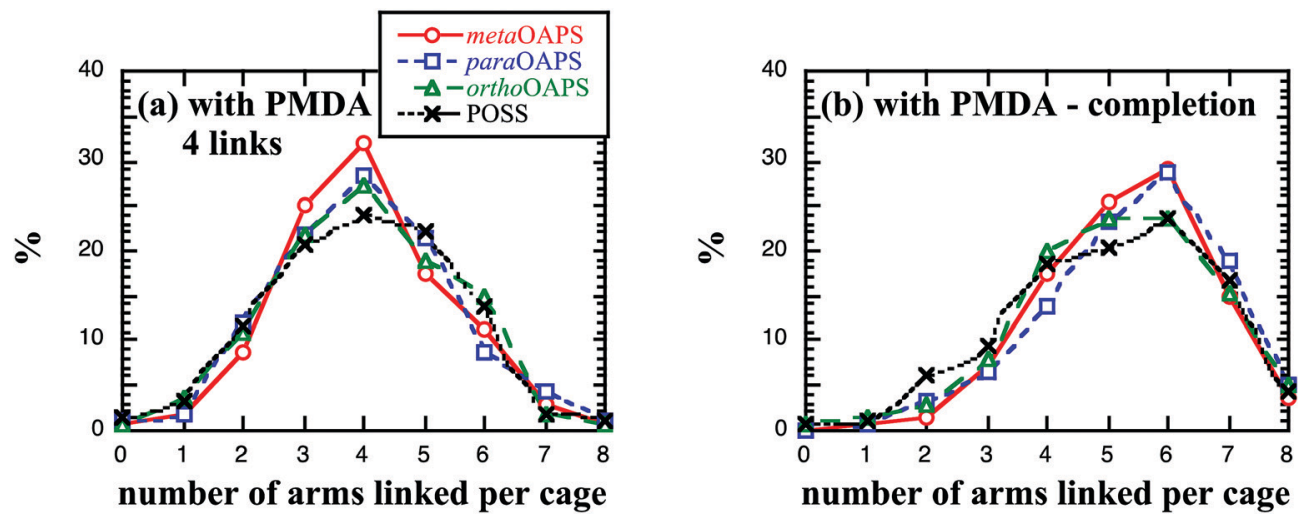

Fig. 8 Probability density distributions for the number of arms linked per cage in the polyOAPS-PMDA and polyPOSS-PMDA networks with either (a) an average connectivity of 4 links per cage or (b) the reactions carried out to completion.

cage presented in Table 5 show that the maximum cross-linking density is $\sim 4$, while an average connectivity of 4 links per cage is closer to an actual cross-linking density of $\sim 3$. Since both an intercage double-link and an intracage link have the same negative effect on the cross-linking density, their effects compensate and the values of Table 5 correlate almost perfectly with the number of intercage links (white bars in Fig. 7). It is also possible to get more complicated structures with either two intracage links or one intracage and one intercage double-link in addition to the intercage single-links, but these remain rare as they lead to high steric restraints.

Fig. 8 and Table 6 give the distributions of the number of arms linked per cage and show that they are skewed fairly uniformly to higher values when the reactions are carried out to completion.

While very few cages remain isolated and trapped in their network ( 0 links), all the other cages are found to have a number of links per cage ranging from 1 to 8 . The largest probabilities are 3, 4 or 5 links for those with an average connectivity of 4 (Fig. 8a) and 4, 5 or 6 links for those with the reactions carried out to completion (Fig. 8b). For steric reasons, it gets increasingly difficult to have more links but there are still a rather significant number of cages having 7 links per cage in the completion case (Table 6). A higher degree of connectivity thus reinforces the network as a whole in an homogeneous way. As seen above, the highest connectivities are obtained with PMDA $>$ ODPA $>6$ FDA, i.e. the relative order of the molecular volumes.

\subsection{Resistances to stress at $300{ }^{\circ} \mathrm{C}$}

Experimental mechanical measurements at high temperatures can be very difficult, ${ }^{39,40}$ but they are a lot more straightforward to carry out on model systems. Since these hyper-cross-linked networks are aimed at preventing excessive volume dilation when subjected to high loadings of plasticizing gases, ${ }^{18}$ the on-diagonal components of their required pressure tensor were

Table 6 Distributions of the numbers of arms linked per cage in the 22 networks under study

\begin{tabular}{|c|c|c|c|c|c|c|c|c|c|c|c|}
\hline $\begin{array}{l}\% \text { Of cage } \\
\text { having }\end{array}$ & $\begin{array}{l}\text { metaOAPS } \\
+ \text { PMDA }\end{array}$ & $\begin{array}{l}\text { paraOAPS } \\
+ \text { PMDA }\end{array}$ & $\begin{array}{l}\text { orthoOAPS } \\
+ \text { PMDA }\end{array}$ & $\begin{array}{l}\text { POSS } \\
+ \text { PMDA }\end{array}$ & $\begin{array}{l}\text { metaOAPS } \\
+6 \mathrm{FDA}\end{array}$ & $\begin{array}{l}\text { paraOAPS } \\
+6 \text { FDA }\end{array}$ & $\begin{array}{l}\text { orthoOAPS } \\
+6 \text { FDA }\end{array}$ & $\begin{array}{l}\text { POSS } \\
+6 \text { FDA }\end{array}$ & $\begin{array}{l}\text { metaOAPS } \\
+ \text { ODPA }\end{array}$ & $\begin{array}{l}\text { paraOAPS } \\
+ \text { ODPA }\end{array}$ & $\begin{array}{l}\text { orthoOAPS } \\
+ \text { ODPA }\end{array}$ \\
\hline \multicolumn{12}{|c|}{ Average connectivity of 4 links per cage } \\
\hline 0 link & 0.5 & 0.9 & 0.5 & 1.4 & 0.5 & 0.5 & 1.4 & 2.3 & 0.5 & 1.4 & 0 \\
\hline 1 link & 1.9 & 1.9 & 3.7 & 3.2 & 3.7 & 4.6 & 1.4 & 4.2 & 3.7 & 4.2 & 2.3 \\
\hline 2 links & 8.8 & 12.0 & 10.7 & 11.6 & 16.7 & 11.6 & 10.2 & 7.9 & 8.8 & 10.2 & 11.1 \\
\hline 3 links & 25.0 & 21.8 & 21.8 & 20.8 & 16.7 & 22.7 & 23.2 & 20.8 & 24.1 & 18.5 & 24.1 \\
\hline 4 links & 31.9 & 28.2 & 27.3 & 24.1 & 24.5 & 23.6 & 28.7 & 26.9 & 24.5 & 29.6 & 24.5 \\
\hline 5 links & 17.6 & 21.3 & 19.0 & 22.2 & 19.4 & 17.6 & 19.9 & 20.8 & 25.5 & 19.9 & 25.9 \\
\hline 6 links & 11.1 & 8.8 & 14.8 & 13.9 & 12.5 & 14.8 & 13.0 & 13.9 & 9.7 & 12.0 & 8.8 \\
\hline 7 links & 2.8 & 4.2 & 1.9 & 1.9 & 5.6 & 4.2 & 1.9 & 3.2 & 3.2 & 3.7 & 3.2 \\
\hline 8 links & 0.5 & 0.9 & 0.5 & 0.9 & 0.5 & 0.5 & 0.5 & 0 & 0 & 0.5 & 0 \\
\hline \multicolumn{12}{|c|}{ Reactions carried out to completion } \\
\hline 0 link & 0 & 0 & 0.5 & 0.5 & 0 & 0 & 0.9 & 0.5 & 0 & 0.5 & 0 \\
\hline 1 link & 0.5 & 0.5 & 1.4 & 0.9 & 1.4 & 1.4 & 0.5 & 2.3 & 0.9 & 1.4 & 0.5 \\
\hline 2 links & 1.4 & 3.2 & 2.8 & 6.0 & 5.6 & 4.2 & 3.7 & 4.6 & 3.2 & 2.8 & 4.6 \\
\hline 3 links & 7.4 & 6.5 & 7.9 & 9.3 & 13.4 & 13.0 & 18.5 & 13.9 & 4.6 & 5.6 & 9.7 \\
\hline 4 links & 17.6 & 13.9 & 19.9 & 18.5 & 22.7 & 19.0 & 24.5 & 13.9 & 17.1 & 16.2 & 23.2 \\
\hline 5 links & 25.5 & 23.2 & 23.6 & 20.4 & 19.0 & 26.4 & 26.9 & 28.2 & 30.1 & 24.5 & 32.9 \\
\hline 6 links & 29.2 & 28.7 & 23.6 & 23.6 & 19.4 & 20.4 & 18.5 & 22.2 & 23.6 & 26.9 & 19.0 \\
\hline 7 links & 14.8 & 19.0 & 15.3 & 16.7 & 13.4 & 13.0 & 5.1 & 11.1 & 17.1 & 17.6 & 8.8 \\
\hline 8 links & 3.7 & 5.1 & 5.1 & 4.2 & 5.1 & 2.8 & 1.4 & 3.2 & 3.2 & 4.6 & 1.4 \\
\hline
\end{tabular}


first reduced linearly at a rate of $-1 \mathrm{bar} \mathrm{ps}^{-1}$ up to $2500 \mathrm{ps}$ in order to assess their resistance to isotropic volume dilation. It has been shown previously ${ }^{71}$ that, although model mechanical properties of polymers are known to be slightly dependent on both the thermal history and the rates of deformation, ${ }^{73-75}$ these effects remains minor in the networks under study. Indeed, the main point is that these systems are being compared under identical conditions. The pressure $v s$. \%volume dilation curves are displayed in Fig. 9 for all 22 systems under study.

At the same average connectivity of four, the resistance to dilation at $300{ }^{\circ} \mathrm{C}$ generally increases with the average number of intercage links (Fig. 7): the meta and para OAPS isomers are favoured with respect to the aliphatic POSS when linked to the rigid PMDA, while the ortho isomer is favoured in the case of the more flexible 6FDA and ODPA linkers. Carrying out the reactions to completion strongly increases the resistance to dilation in all OAPS-based systems, and to a lesser extent in the POSS-based systems. It shows how a fairly limited increase in the average connectivity (Fig. 7 and Table 3) is fundamental in attaining the highest possible thermoresistances. As far as the organic linkers are concerned, the networks with the shorter and stiffer PMDA moiety are more efficient than those based on the 6FDA or ODPA linkers. (a) with PMDA - 4 links

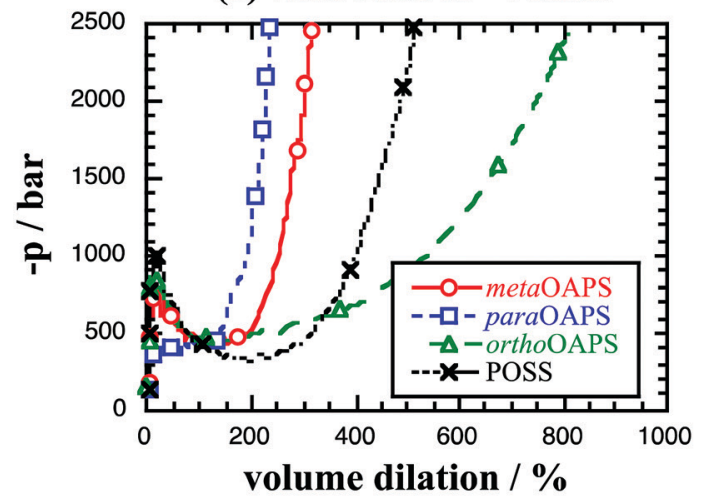

(c) with 6FDA - 4 links

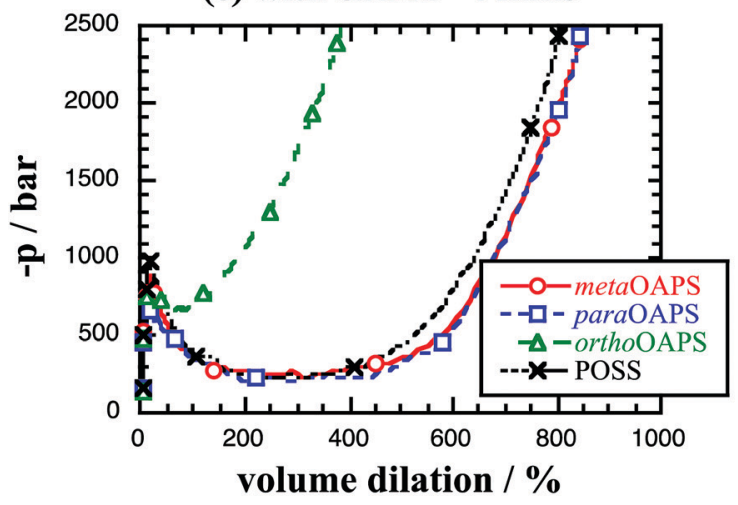

(e) with ODPA - 4 links

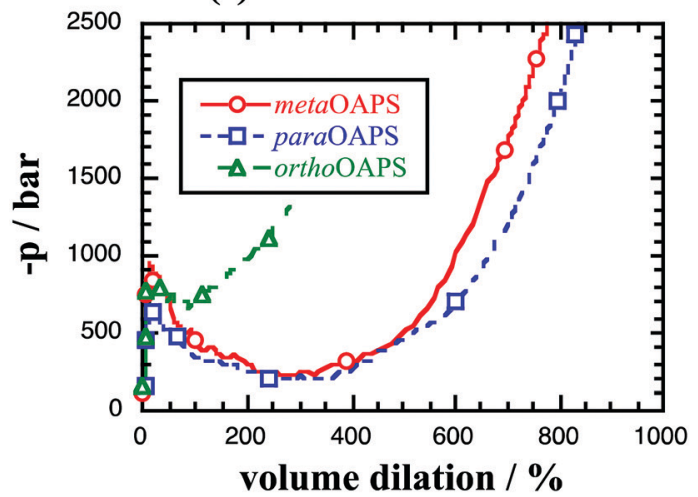

(b) with PMDA - completion

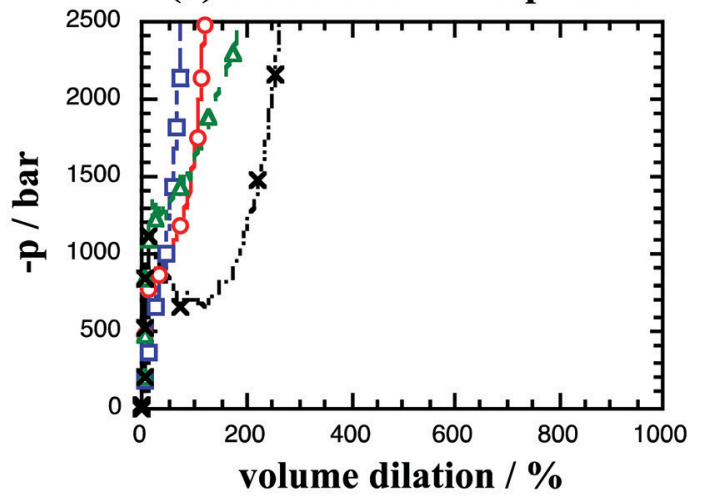

(d) with 6FDA - completion

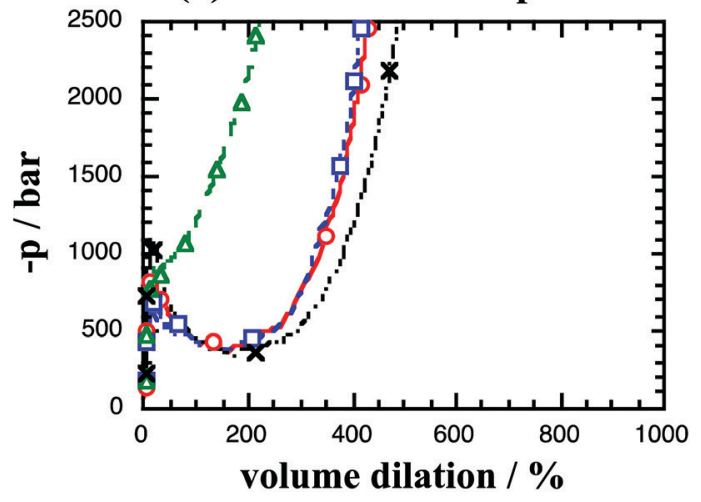

(f) with ODPA - completion

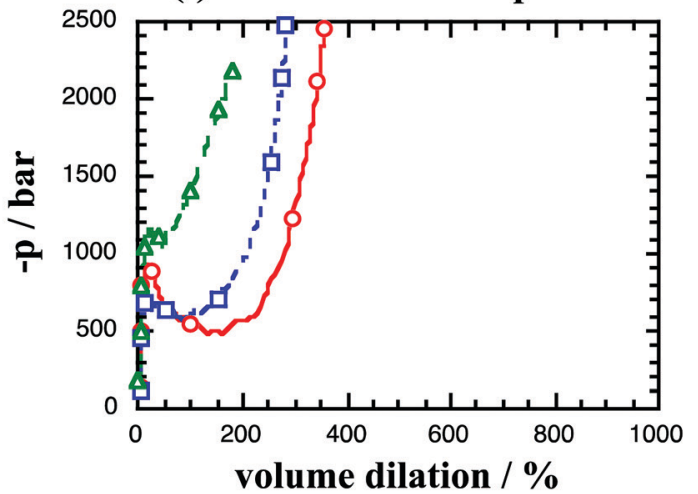

Fig. 9 Isotropic dilation at $300{ }^{\circ} \mathrm{C}$ for the polyOAPS-imides and polyPOSS-imides networks with an average connectivity of 4 links per cage (left figures) or with the reactions carried out to completion (right figures). 
Fig. 10 compares the resistance to dilation of the inorganic parts of the linkers, monitored by the behaviour of the average Si $\cdots \mathrm{N}$ distance (left figures), to that of the organic parts, monitored by the behaviour of the average $\mathrm{N} \cdots \mathrm{N}$ distance (right figures), for the 11 networks with the reactions carried out to completion; the corresponding data for the networks with the average connectivity of 4 are displayed in Fig. S9 of the ESI. $\dagger$ It shows that both the meta and the para arms of the inorganic OAPS precursor are very resistant to dilation. The $\mathrm{Si} \cdots \mathrm{N}$ average distance increases slightly in the ortho arms due to slight rotations around the bond between the phenyl carbon and the imide $\mathrm{N}$, but these are their only effective degrees of freedom. Indeed, the ortho-based systems are generally the most resistant ones (Fig. 9). On the other hand, the aliphatic arms of the POSS precursor deform upon dilation, thus showing that the OAPS precursor is indeed the right way towards increased thermoresistance. However, the general behaviour also strongly depends on the organic linkers. Both the flexible imides adapt to dilation by stretching (Fig. 10d and e), with 6FDA being generally less resistant than ODPA. PMDA is only able to stretch a very small amount (Fig. 10b) due to its inherently stiff structure. PMDA combined with OAPS thus gives a better thermoresistance. (a) with PMDA - inorganic linker

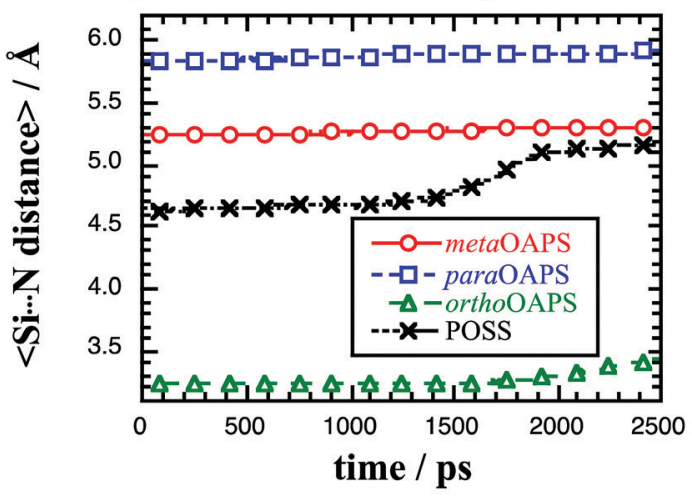

(c) with 6FDA - inorganic linker

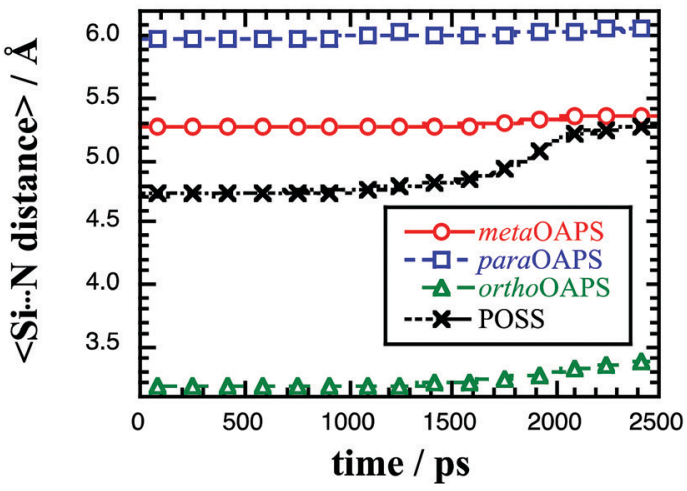

(e) with ODPA - inorganic linker

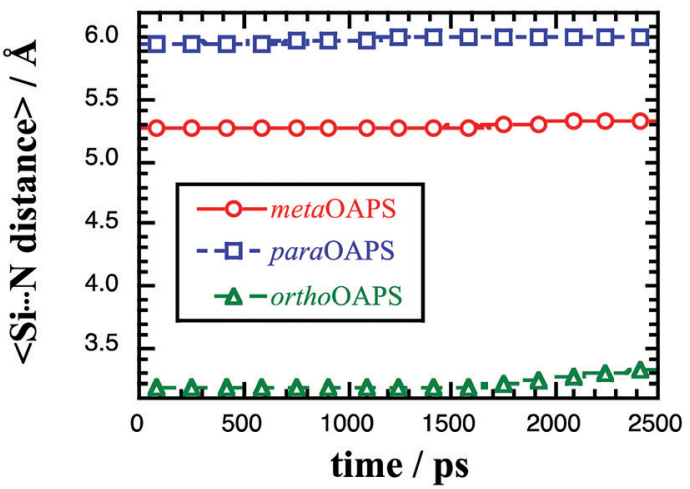

(b) with PMDA - organic linker

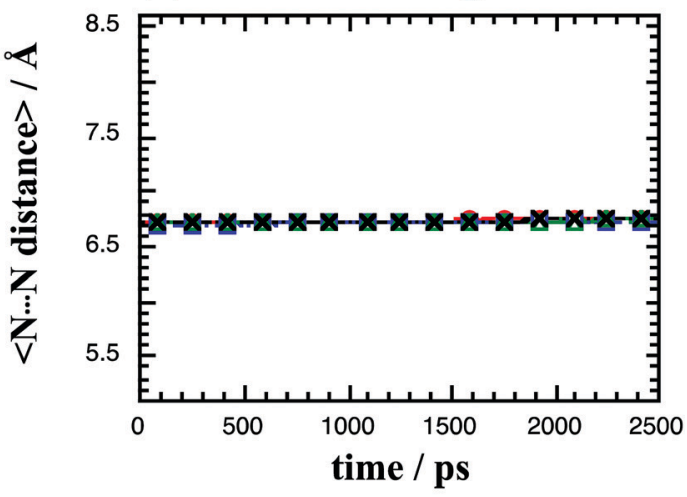

(d) with 6FDA - organic linker

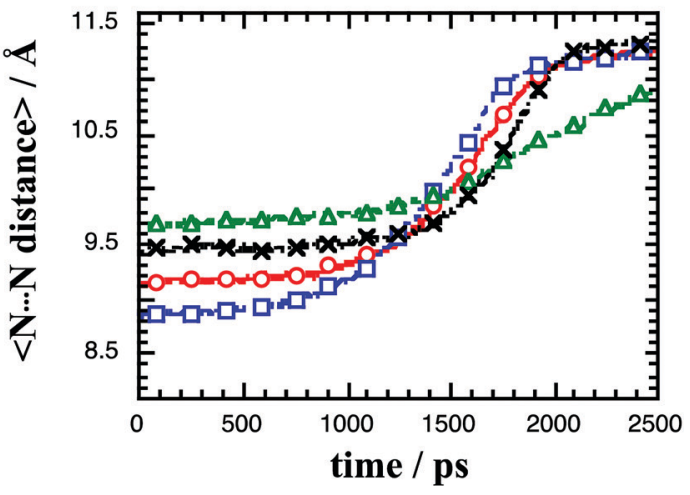

(f) with ODPA - organic linker

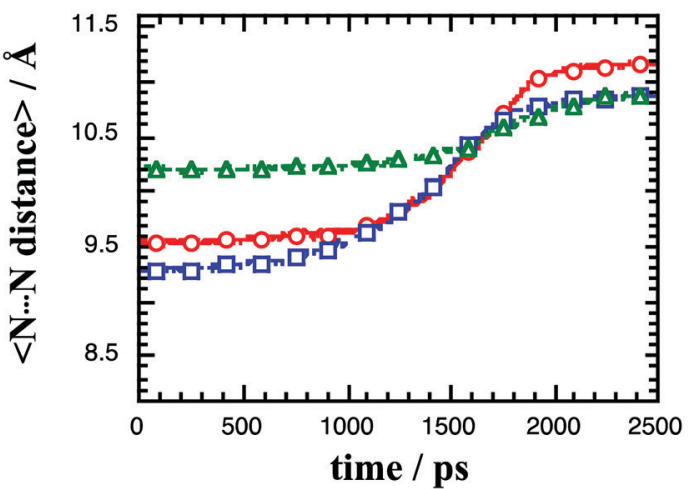

Fig. 10 Time-evolution upon dilation of the average Si $\cdots \mathrm{N}$ distance, representing the inorganic part of the linker (left figures), and the average $\mathrm{N} \cdots \mathrm{N}$ distance, representing the organic part of the linker (right figures), for all the networks where reactions have been carried out to completion. 
(a) with PMDA

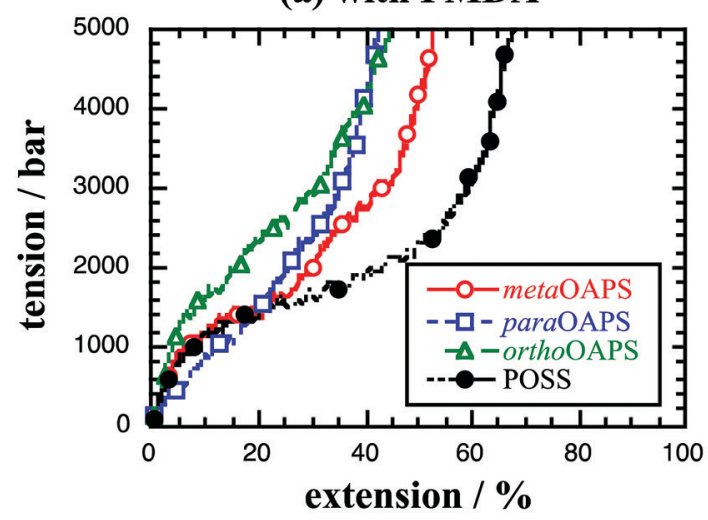

(c) with 6FDA

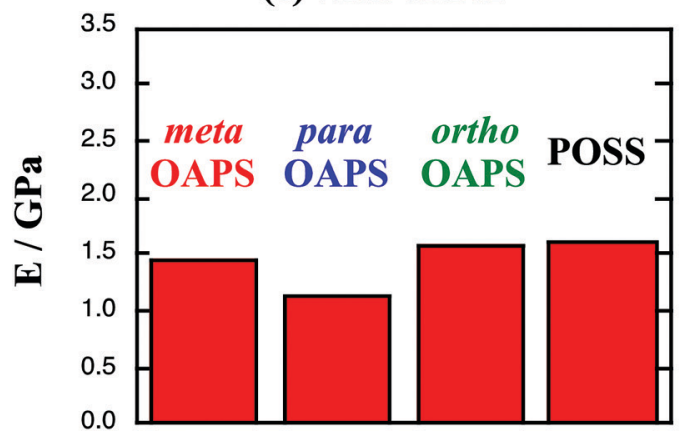

(b) with PMDA

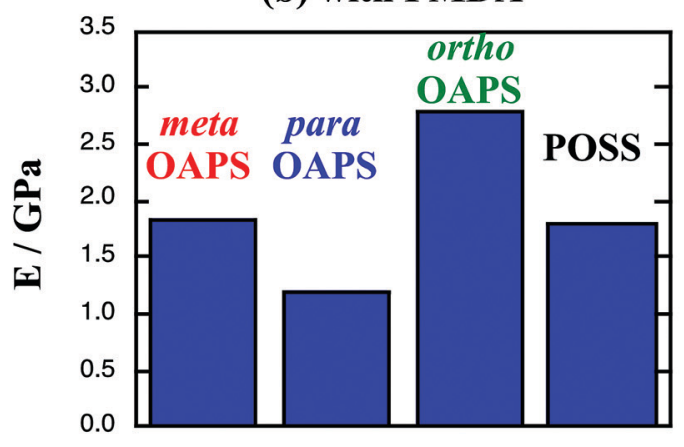

(d) with ODPA

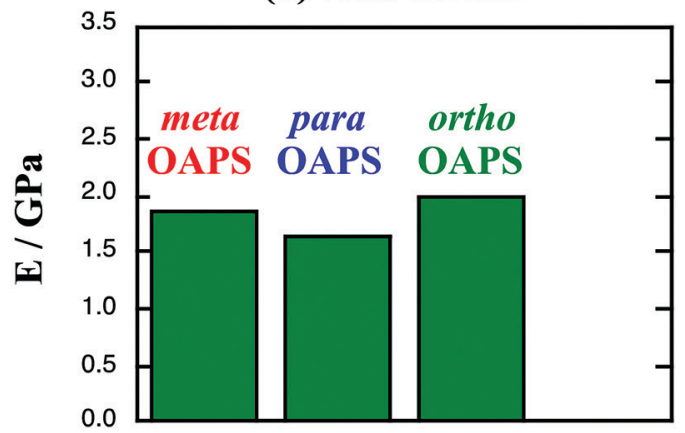

Fig. 11 Resistance to tension at $300{ }^{\circ} \mathrm{C}$ for all networks where the reactions have been carried out to completion: (a) stress-strain curves for the polyOAPS-PMDA and polyPOSS-PMDA, $(b-d)$ average Young's moduli $E$ for the networks based on PMDA, 6FDA and ODPA respectively. The maximum standard error on $\mathrm{E}$ is $0.04 \mathrm{GPa}$.

To complement the isotropic dilation, uniaxial extension tests were also made by changing the tension in the $y$ direction at a rate of 1 bar $\mathrm{ps}^{-1}$ for $\sim 5000 \mathrm{ps}$ at $300{ }^{\circ} \mathrm{C}$ for the most promising systems, i.e. those with the cross-linking reactions carried out to completion (Fig. 9 and 10). There again, tests made using 0.1 bar $\mathrm{ps}^{-1}$ did not make much difference. ${ }^{71}$ The stress-strain curves for the PMDA-based systems at $300{ }^{\circ} \mathrm{C}$ are displayed in Fig. 11a. When subjected to tension at high temperature, the hyper-cross-linked networks deform with no apparent yield stress but this is soon followed by a strain hardening stage which occurs at lower strains in the polyOAPS-imides. Fig. 11b-d compare their average model Young's moduli, E, at $300{ }^{\circ} \mathrm{C}$, whose orders of magnitude are consistent with those found experimentally for thermosets and nanocomposites. ${ }^{29,30,39}$ As far as the inorganic precursor is concerned, the Young's moduli vary in the order paraOAPS <
POSS $\approx$ metaOAPS $<$ orthoOAPS, which correlates with the relative order of the densities (Table 3), i.e. with the intrinsic cohesion. For the organic precursor, the order follows that of the rigidity, i.e. 6FDA $<$ ODPA $<$ PMDA, in agreement with the dilation tests (Fig. 9 and 10).

\section{Behaviour of the polyOAPS-imides at $400{ }^{\circ} \mathrm{C}$}

The experimental onset of decomposition for the polyPOSSimides at $\sim 350{ }^{\circ} \mathrm{C}$ has been related to the aliphatic links in the initial POSS precursor. ${ }^{24}$ The aromatic rings in OAPS should displace the start of the decomposition towards higher temperatures, ${ }^{40}$ and allow for the use of the networks up to at least $400{ }^{\circ} \mathrm{C}$. Indeed, the degradation temperature for OAPS/

Table 7 Average model network densities, interOAPS Si $\cdots$ Si distances and imide $\mathrm{N} \cdots$ centre $\cdots \mathrm{N}$ angles and Young's moduli $\mathrm{E}$ at $400{ }^{\circ} \mathrm{C}$ for the nine polyOAPS-imides with the cross-linking reactions carried out to completion

\begin{tabular}{|c|c|c|c|c|c|c|c|c|c|}
\hline & $\begin{array}{l}\text { metaOAPS } \\
+ \text { PMDA }\end{array}$ & $\begin{array}{l}\text { paraOAPS } \\
+ \text { PMDA }\end{array}$ & $\begin{array}{l}\text { orthoOAPS } \\
+ \text { PMDA }\end{array}$ & $\begin{array}{l}\text { metaOAPS } \\
+6 \mathrm{FDA}\end{array}$ & $\begin{array}{l}\text { paraOAPS } \\
+6 \text { FDA }\end{array}$ & $\begin{array}{l}\text { orthoOAPS } \\
+6 \text { FDA }\end{array}$ & $\begin{array}{l}\text { metaOAPS } \\
+ \text { ODPA }\end{array}$ & $\begin{array}{l}\text { paraOAPS } \\
+ \text { ODPA }\end{array}$ & $\begin{array}{l}\text { orthoOAPS } \\
+ \text { ODPA }\end{array}$ \\
\hline$\left\langle\rho_{\text {network }}\right\rangle$ in $\mathrm{g} \mathrm{cm}^{-3}( \pm 0.002)$ & 1.044 & 0.882 & 1.254 & 1.181 & 1.128 & 1.198 & 1.141 & 1.080 & 1.175 \\
\hline$\langle\mathrm{Si} \cdots \mathrm{Si}$ distances $\rangle$ in $\AA( \pm 0.01)$ & 15.49 & 16.88 & 11.18 & 15.36 & 16.03 & 13.80 & 15.70 & 16.76 & 14.27 \\
\hline$\langle\mathrm{N} \cdots$ centre $\cdots \mathrm{N}$ angles $\rangle$ in deg $( \pm 0.1)$ & 132.9 & 132.3 & 133.0 & 99.8 & 96.0 & 107.7 & 110.5 & 106.6 & 122.6 \\
\hline$E$ in $\mathrm{GPa}( \pm 0.04)$ & 1.64 & 1.16 & 2.11 & 1.11 & 1.04 & 1.37 & 1.36 & 1.17 & 1.58 \\
\hline
\end{tabular}


(a) with PMDA

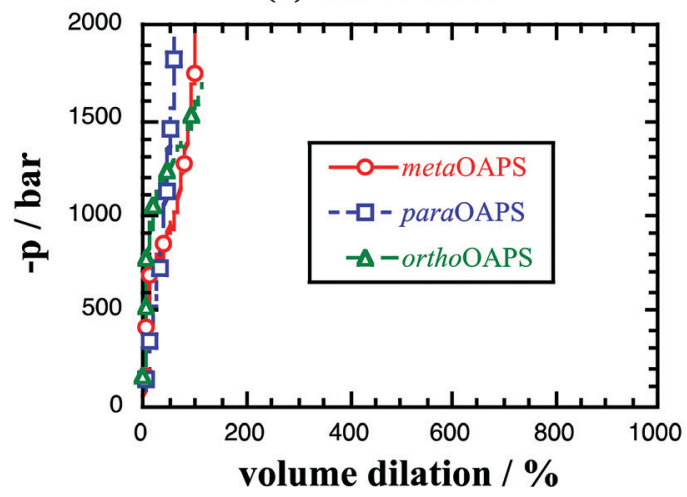

(b) with 6FDA

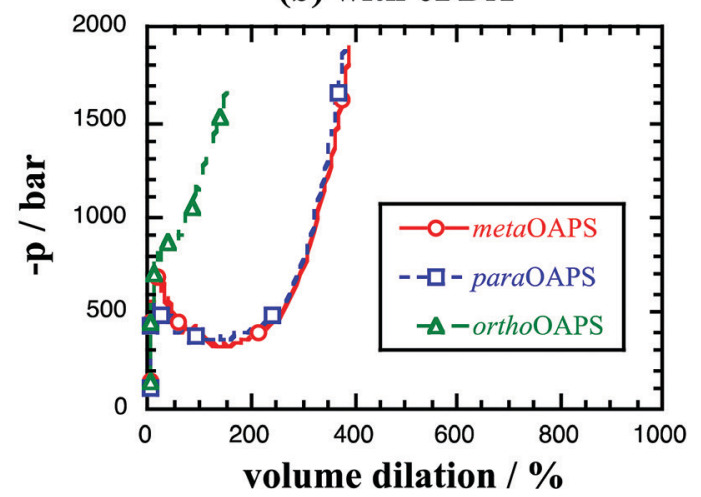

(c) with ODPA

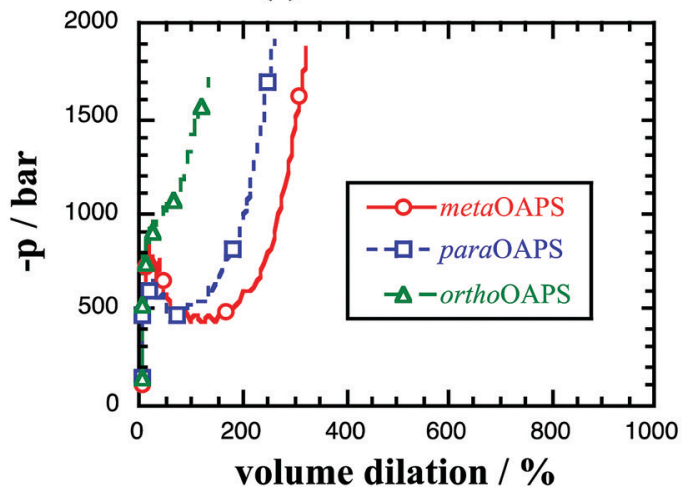

Fig. 12 Isotropic dilation at $400{ }^{\circ} \mathrm{C}$ for the polyOAPS-imides with the reactions carried out to completion.

polyimide nanocomposites has been shown to be close to $500{ }^{\circ} \mathrm{C} .{ }^{37,38}$ To assess whether the resistance is maintained under harsher conditions, the nine polyOAPS-imides with the reactions carried out to completion were heated from $300{ }^{\circ} \mathrm{C}$ to $400{ }^{\circ} \mathrm{C}$. The sytems relaxed relatively fast and the production runs continued until 5 ns (Fig. S10 in the ESI $\dagger$ ). The properties were averaged over the last ns and isotropic dilation and tension tests were carried out at $400{ }^{\circ} \mathrm{C}$ in the same way than at $300{ }^{\circ} \mathrm{C}$.

Table 7 displays the average results found at $400{ }^{\circ} \mathrm{C}$ for the model properties analysed at $300{ }^{\circ} \mathrm{C}$ (Section 3). These include the densities (Table 3), the characteristic distances and angles for the intercage links (Table 4) and the Young's moduli (Fig. 11). The energies at $400{ }^{\circ} \mathrm{C}$ are reported in Table S6 of the ESI. $\dagger$

With respect to $300{ }^{\circ} \mathrm{C}$, the $\rho_{\text {network }}$ and E decrease while the Si $\cdots$ Si distances and $\mathrm{N} \cdots$ centre $\cdots \mathrm{N}$ angles are slightly more stretched. However, there are no signs of a collapse in the structures and this is confirmed by the isotropic dilation results at $400{ }^{\circ} \mathrm{C}$, which are displayed in Fig. 12 for the same range of volume dilations than in Fig. $9 \mathrm{~b}-\mathrm{f}$ at $300{ }^{\circ} \mathrm{C}$. They clearly show that these systems maintain their good resistance up to $400{ }^{\circ} \mathrm{C}$.

\section{Conclusions}

This work screens a series of hybrid organic-inorganic polyOAPS-imide model networks based on the meta, para and ortho isomers of OAPS combined with three different organic precursors, the PMDA, the 6FDA and the ODPA dianhydrides. It stems from the recent experimental development ${ }^{21-24}$ of hyper-cross-linked thin films based on an initial POSS precursor with aliphatic arms. Such polyPOSS-imide networks were aimed at gas separation applications under high-temperature and/or high-pressure conditions, but the $-\left(\mathrm{CH}_{2}\right)_{3}$ - arms were identified as a weak link in the structures. ${ }^{29,30}$ Their replacement by a phenyl ring in OAPS should increase the thermoresistance, even if it introduces extra degrees of complexity. Indeed, the functional $-\mathrm{NH}_{2}$ group on the monosubstituted phenyl ring can either be attached at a meta, a para or an ortho position.

To investigate the effects of the OAPS isomers, twenty-two model networks were generated from different precursor mixtures at room temperature. Nine polyOAPS-imide models were built for all possible permutations of OAPS isomer and dianhydride pairs. These were compared with a polyPOSSPMDA and a polyPOSS-6FDA constructed under the same conditions. The models were first cross-linked up to the initially-determined $^{22}$ experimental average value of 4 links per cage, but a second set was allowed to form cross-links up to completion. The latter is a lot more expensive in terms of cross-linking simulation time but it mimicks the maximum cross-linking density that can be obtained experimentally by varying the concentrations of the contacting solutions. ${ }^{23}$ The cross-linked networks were then relaxed at $300{ }^{\circ} \mathrm{C}$ to be consistent with the experimental imidization treatment. 
Since these systems are aimed at being thermomechanically resistant, they were screened under harsh conditions, i.e. directly at $300{ }^{\circ} \mathrm{C}$, and the nine most-promising polyOAPSimides were further tested at $400{ }^{\circ} \mathrm{C}$.

Such complex hyper-cross-linked networks include intercage single-links and double-links, which reinforce the structures, and intracage links, which have the opposite effect. The relative percentages of inter- $v s$. intracage links vary depending both on the inorganic precursor and on the flexibility of the dianhydride, with the best structures being generally based on orthoOAPS as the inorganic precursor and on PMDA as the organic precursor. As expected, there are more links in the systems allowed to crosslink until completion, but there is no tendency for the increased number of reactions to favour intercage rather than intracage links. Interestingly, the metaOAPS and paraOAPS behave in a similar way while the orthoOAPS is quite different. Both flexible organic linkers, 6FDA and ODPA, also behave similarly to each other while the shorter and stiffer PMDA imparts extra resistance to mechanical deformation.

Carrying out the cross-linking reactions to completion significantly improves the resistance to dilation at $300{ }^{\circ} \mathrm{C}$. The POSS with the aliphatic arms as well as the 6FDA and ODPA linkers were found to be prone to large deformations. On the other hand, the orthoOAPS, metaOAPS, paraOAPS and PMDA are hardly extensible and thus prevent volume dilation. When submitted to uniaxial tension, the Young's moduli varied in the order paraOAPS $<$ POSS $\approx$ metaOAPS $<$ orthoOAPS for the inorganic precursor, in agreement with the same relative order for their cohesion. For the organic precursor, the resistance was inversely correlated to their degrees of flexibility and varied in the order 6FDA < ODPA < PMDA. There again, the networks based on either orthoOAPS and/or PMDA showed superior resistance to the others.

All the polyOAPS-imides with the cross-linking reactions carried out to completion were further heated and tested at $400{ }^{\circ} \mathrm{C}$, which is closer to the expected onset of decomposition. They confirmed the trends found at $300{ }^{\circ} \mathrm{C}$ and showed no signs of structural collapse. These systems are thus very promising under harsh conditions. Their respective gas sorption capabilities will be reported in a following work.

\section{Author contributions}

S. Neyertz: conceptualization, funding acquisition, resources, supervision, methodology, investigation, formal analysis, writing - original draft. S. Salimi: investigation, writing - review \& editing. F. Radmanesh: writing - review\&editing. N. E. Benes: conceptualization, funding acquisition, supervision, writing review \& editing. D. Brown: software, methodology, investigation, formal analysis, writing - review\&editing.

\section{Conflicts of interest}

There are no conflicts to declare.

\section{Acknowledgements}

This work is part of the MOLHYB project financed by the French ANR (Agence Nationale de la Recherche) within the framework of the AAPG (Appel à Projets Générique) 2018. It had access to the HPC resources of CCRT/CINES/IDRIS under the allocations A007- and A009-095053 made by GENCI, France. The MUST computing centre at the University Savoie Mont Blanc, France, is also acknowledged for the provision of computer time. Nicolas Charvin is thanked for his help with the installation and maintenance of the laboratory local servers and Lara Perrin for her advice about polymer synthesis.

\section{Notes and references}

1 Y. Yampolskii, I. Pinnau and B. D. Freeman, Materials Science of Membranes for Gas and Vapor Separation, John Wiley \& Sons Ltd., Chichester, UK, 2006.

2 M. Galizia, W. S. Chi, Z. P. Smith, T. C. Merkel, R. W. Baker and B. D. Freeman, Macromolecules, 2017, 50, 7809-7843.

3 D. S. Sholl and R. P. Lively, Nature, 2016, 532, 435-437.

4 J. Hennessy, Nat. Mater., 2017, 16, 280-282.

5 M. Calle, C. M. Doherty, A. J. Hill and Y. M. Lee, Macromolecules, 2013, 46, 8179-8189.

6 A. Bos, I. G. M. Pünt, M. Wessling and H. Strathmann, J. Membr. Sci., 1999, 155, 67-78.

7 M. Wessling, M. Lidon Lopez and H. Strathmann, Sep. Purif. Technol., 2001, 24, 223-233.

8 B. S. R. Reddy, Advances in Nanocomposites - Synthesis, Characterization and Industrial Applications, InTech, Rijeka, Croatia, 2011.

9 D. B. Cordes, P. D. Lickiss and F. Rataboul, Chem. Rev., 2010, 110, 2081-2173.

10 F. Männle, T. Tofteberg, M. Skaugen, H. Bu, T. Peters, P. D. C. Dietzel and M. Pilz, J. Nanopart. Res., 2011, 13, 4691-4701.

11 R. M. Laine and M. F. Roll, Macromolecules, 2011, 44, 1073-1109.

12 Y. Du and H. Liu, Dalton Trans., 2020, 49, 5396-5405.

13 K. N. Raftopoulos and K. Pielichowski, Prog. Polym. Sci., 2016, 52, 136-187.

14 P. Iyer, G. Iyer and M. Coleman, J. Membr. Sci., 2010, 358, 26-32.

15 D. M. Pinson, G. R. Yandek, T. S. Haddad, E. M. Horstman and J. M. Mabry, Macromolecules, 2013, 46, 7363-7377.

16 M. G. Mohamed and S.-W. Kuo, Polymers, 2019, 11, 26.

17 Z. Lan, X. Chen, X. Zhang, C. Zhu, Y. Yu and J. Wei, Polymers, 2019, 11, 1058.

18 X. Chen and L. F. Dumée, Adv. Eng. Mater., 2019, 21, 1800667.

19 N. Hao, M. Böhning and A. Schönhals, Macromolecules, 2010, 43, 9417-9425.

20 M. M. Raman, V. Filiz, M. M. Khan, B. N. Gacal and V. Abetz, React. Funct. Polym., 2015, 86, 125-133.

21 M. J. T. Raaijmakers, M. Wessling, A. Nijmeijer and N. E. Benes, Chem. Mater., 2014, 26, 3660-3664. 
22 M. J. T. Raaijmakers, M. A. Hempenius, P. M. Schön, G. J. Vancso, A. Nijmeijer, M. Wessling and N. E. Benes, J. Am. Chem. Soc., 2014, 136, 330-335.

23 M. J. T. Raaijmakers, W. Ogieglo, M. Wiese, M. Wessling, A. Nijmeijer and N. E. Benes, ACS Appl. Mater. Interfaces, 2015, 7, 26977-26988.

24 M. J. T. Raaijmakers, E. J. Kappert, A. Nijmeijer and N. E. Benes, Macromolecules, 2015, 48, 3031-3039.

25 Q. H. Hussein, P. De Wit, E. J. Kappert and N. E. Benes, ACS Sustainable Chem. Eng., 2015, 3, 3454-3460.

26 E. Maaskant, P. De Wit and N. E. Benes, J. Membr. Sci., 2018, 550, 296-301.

27 L. Ansaloni, E. Louradour, F. Radmanesh, H. van Veen, M. Pilz, C. Simon, N. E. Benes and T. A. Peters, J. Membr. Sci., 2021, 620, 118875.

28 M. K. Ghosh and K. L. Mittal, Polyimides: Fundamentals and Applications, Marcel Dekker, Inc., New York, 1996.

29 S. Neyertz, D. Brown, M. J. T. Raaijmakers and N. E. Benes, Comput. Mater. Sci., 2016, 117, 338-353.

30 S. Neyertz, D. Brown, M. J. T. Raaijmakers and N. E. Benes, Phys. Chem. Chem. Phys., 2016, 18, 28688-28703.

31 R. S. Murali, T. Sankarshana and S. Sridhar, Sep. Purif. Rev., 2013, 42, 130-186.

32 X.-M. Jia, H.-J. Qian and Z.-Y. Lu, Phys. Chem. Chem. Phys., 2020, 22, 11400.

33 R. Tamaki, Y. Tanaka, M. Z. Asuncion, J. Choi and R. M. Laine, J. Am. Chem. Soc., 2001, 123, 12416-12417.

34 D. M. Anstine, A. G. Demidov, N. F. Mendez, W. J. Morgan and C. M. Colina, J. Membr. Sci., 2020, 599, 117798.

35 S. Neyertz and D. Brown, J. Membr. Sci., 2020, 614, 118478.

36 D. Brown, S. Neyertz, M. J. T. Raaijmakers and N. E. Benes, J. Membr. Sci., 2019, 577, 113-119.

37 J. Yao, S. Ma, J. Zhang, Y. Wang, C. Wang, H. Zhou, C. Chen and G. Liu, eXPRESS Polym. Lett., 2021, 15, 433-444.

38 S. Nagendiran, A. Chandramohan, K. Dinakaran and M. Alagar, J. Macromol. Sci., Part A: Pure Appl. Chem., 2019, 56, 1082-1096.

39 J. Choi, R. Tamaki, S. G. Kim and R. M. Laine, Chem. Mater., 2003, 15, 3365-3375.

40 R. Tamaki, J. Choi and R. M. Laine, Chem. Mater., 2003, 15, 793-797.

41 S. G. Kim, J. Choi, R. Tamaki and R. M. Laine, Polymer, 2005, 46, 4514-4524.

42 J. K. Koech, Q. Shao, F. N. Mutua and Y. Wang, Adv. Chem. Eng. Sci., 2013, 3, 93-97.

43 J.-C. Huang, C.-B. He, Y. Xiao, K. Y. Mya, J. Dai and Y. P. Siow, Polymer, 2003, 44, 4491-4499.

44 P. S. G. Krishnan and C. He, J. Polym. Sci., Part A: Polym. Chem., 2005, 43, 2483-2494.

45 B. Govindaraj, P. Sundararajan and M. Sarojadevi, Polym. Int., 2011, 61, 1344-1352.

46 M. Y. Lo, K. Ueno, H. Tanabe and A. Sellinger, Chem. Rec., 2006, 6, 157-168.

47 Y. Zhang, S. H. Lee, M. Yoonessi, H. Toghiani and C. U. Pittman Jr., J. Inorg. Organomet. Polym., 2007, 17, 159-171.
48 A. Lee, T. S. Haddad, J. J. Schwab and Y. Z. An, available at https://www.researchgate.net/publication/277880144, 2006.

49 C. Wu and W. Xu, Polymer, 2006, 47, 6004-6009.

50 V. Varshney, S. S. Patnaik, A. K. Roy and B. L. Farmer, Macromolecules, 2008, 41, 6837-6842.

51 N. Lacevic, R. H. Gee, A. Saab and R. Maxwell, J. Chem. Phys., 2008, 129, 124903.

52 P.-H. Lin and R. Khare, Macromolecules, 2009, 42, 4319-4327.

53 P.-H. Lin and R. Khare, J. Therm. Anal. Calorim., 2010, 102, 461-467.

54 N. B. Shenogina, M. Tsige, S. S. Patnaik and S. M. Mukhopadhyay, Macromolecules, 2012, 45, 5307-5315.

55 L. J. Abbott and C. M. Colina, Macromolecules, 2011, 44, 4511-4519.

56 A. Bandyopadhyay, P. K. Valavala, T. C. Clancy, K. E. Wise and G. M. Odegard, Polymer, 2011, 52, 2445-2452.

57 J. H. Moon, A. R. Katha, S. Pandian, S. M. Kolake and S. Han, J. Membr. Sci., 2014, 461, 89-95.

58 C. Jang, T. W. Sirk, J. W. Andzelm and C. F. Abrams, Macromol. Theory Simul., 2015, 24, 260-270.

59 S. Pandiyan, J. Krajniak, G. Samaey, D. Roose and E. Nies, Comput. Mater. Sci., 2015, 106, 29-37.

60 Y. Sun, Y. Guo and H. Yang, Mol. Simul., 2020, 46, 121-127.

61 D. Brown, The gmq User Manual Version 6, available at http://www.lmops.univ-savoie.fr/brown/gmq.html, 2021.

62 K. D. Hammonds and J.-P. Ryckaert, Comput. Phys. Commun., 1991, 62, 336-351.

63 G. Ciccotti, M. Ferrario and J. P. Ryckaert, Mol. Phys., 1982, 47, 1253-1264.

64 M. Clark, R. D. Cramer III and N. Van Opdenbosch, J. Comput. Chem., 1989, 10, 982-1012.

65 A. Striolo, C. McCabe and P. T. Cummings, Macromolecules, 2005, 38, 8950-8959.

66 Z. A. Makrodimitri, R. Dohrn and I. G. Economou, Macromolecules, 2007, 40, 1720-1729.

67 H. J. C. Berendsen, J. P. M. Postma, W. F. Van Gunsteren, A. DiNola and J. R. Haak, J. Chem. Phys., 1984, 81, 3684-3690.

68 D. Brown and J. H. R. Clarke, Comput. Phys. Commun., 1991, 62, 360-369.

69 W. Humphrey, A. Dalke and K. Schulten, J. Mol. Graphics, 1996, 14, 33-38.

70 Y. Zhang, N. E. Benes and R. G. H. Lammertink, Lab Chip, 2015, 15, 575-580.

71 S. Neyertz, D. Brown, M. Pilz, N. Rival, B. Arstad, F. Männle and C. Simon, J. Phys. Chem. B, 2015, 119, 6433-6447.

72 Q. Li, X. Fang, Z. Wang, L. Gao and M. Ding, J. Polym. Sci., Part A: Polym. Chem., 2003, 41, 3249-3260.

73 A. V. Lyulin and M. A. J. Michels, Phys. Rev. Lett., 2007, 99, 085504.

74 C. Li and A. Strachan, Polymer, 2011, 52, 2920-2928.

75 S. V. Lyulin, S. V. Larin, A. A. Gurtovenko, V. M. Nazarychev, S. G. Falkovich, V. E. Yudin, V. M. Svetlichnyi, I. V. Gofman and A. V. Lyulin, Soft Matter, 2014, 10, 1224-1232. 